\title{
Quench Protection and Magnet Power Supply Requirements For the MICE Focusing and Coupling Magnets
}

\author{
Michael A. Green \\ Lawrence Berkeley National Laboratory \\ Berkeley CA 94720, USA \\ Holger Witte \\ Oxford University Physics Department \\ Oxford, OX1-3RH, UK
}

8 June 2005*

\begin{abstract}
This report discusses the quench protection and power supply requirements of the MICE superconducting magnets. A section of the report discusses the quench process and how to calculate the peak voltages and hotspot temperature that result from a magnet quench. A section of the report discusses conventional quench protection methods. Thermal quench back from the magnet mandrel is also discussed. Selected quench protection methods that result in safe quenching of the MICE focusing and coupling magnets are discussed. The coupling of the MICE magnets with the other magnets in the MICE is described. The consequences of this coupling on magnet charging and quenching are discussed. Calculations of the quenching of a magnet due quench back from circulating currents induced in the magnet mandrel due to quenching of an adjacent magnet are discussed. The conclusion of this report describes how the MICE magnet channel will react when one or magnets in that channel are quenched.
\end{abstract}

\section{TABLE OF CONTENTS}

$\begin{array}{lc}\text { Abstract } & \text { Page } \\ \text { Introduction } & 1 . \\ \text { Quench Propagation Velocity and the Hot Spot Temperature } & 2 . \\ \text { Active Quench Protection using a Resistor } & 3 . \\ \text { Quench Propagation in the Magnet Coils } & 9 . \\ \text { Coil Quench Back from the Aluminum Mandrel } & 12 . \\ \text { Passive Quenches in the Focusing and Coupling Magnets } & 14 . \\ \text { Magnetic Coupling between Various Magnets in MICE } & 21 . \\ \text { Magnet Power Supply Design Parameters } & 28 . \\ \text { Magnet Quench Back due to Inductive Coupling to the Mandrels } & 34 . \\ \text { Concluding Comments } & 35 . \\ \text { Acknowledgements } & 45 . \\ \text { References } & 46 .\end{array}$

* Last revision 17 June 2005 


\section{Introduction}

The superconducting magnets in the MICE channel may be connected to other coils of that in series [1], [2]. A quench of one magnet in the string will result in all magnets in the string being dumped. A quench of one magnet may turn the other magnets in the string normal through quench back. If the other magnets in the string are not quenched through quench back, the stored magnetic energy in all of the magnets in the string will end up in the magnet that quenches. The report will discuss the advisability of hooking the various types of magnet coils in series. Quench protection methods that allow the coil to be hooked up in series will be described.

There are two problems that are caused by the quenching of a superconducting magnet or a string of magnets. The first problem is the need to keep the temperature of the magnet hot spot (the place where the magnet quench started) below about $400 \mathrm{~K}$. Excessive hot spot temperatures will result in insulation failure and even a melting of the conductor. The second issue is the voltages developed turn to turn, layer to layer and to ground during the quench process. Excessive voltages can cause a voltage breakdown and arcing. An arc will direct the stored energy of the magnet to the place where it occurs and cause the coil to melt.

The two requirements of a magnet quench protection system (whether it be active or passive) are that the hot spot temperature in the coil where the quench starts be no more than 350 to $400 \mathrm{~K}$ and that the layer to layer voltage be less than say $500 \mathrm{~V}$ and that the voltage to ground be less than $1500 \mathrm{~V}$. (In a potted magnet, these voltage limits can be raised somewhat. Conventional quench protection methods such as putting a resistor across the coil to extract the magnet energy will produce high voltages to ground when the hot spot temperatures are low and vice versa. The most desirable way to protect the magnet is quench the entire coil quickly, so that the magnet stored-energy is put into the coils. This has the effect of reducing the hot spot temperature and reducing the voltages within the coil. The most desirable quench protection method for the MICE magnets is one that is completely passive. (A passive quench protection method does not need a quench detector, which in turn causes something to happen which caused the coil to quench safely.) Passive quench protection methods are inherently safe and are usually less expensive to implement, particularly in DC magnets.

The inductive coupling of one magnet to another affect the quench process and the way the magnet is regulated by its power supply. One cannot design a power supply for a MICE magnet or a string of MICE magnets without understanding the inductive coupling between the coil or coils being powered and all of the other coils in MICE.

The inductive coupling between a magnet and its mandrel can cause quench back in the coil or any other coil in the string thus speeding up the quench process and reducing the magnet voltages and the hot spot temperature of the coil that the quench starts in.

Inductive coupling between MICE coils can cause other coil or strings of coils not involved in the quench to go normal. Inductive coupling may cause all of the MICE magnets to quench when one magnet quenches. Two factors come into play. First a quench in one magnet can cause the current in an adjacent magnet to rise above its critical current. Second, a quench in one magnet can cause a circulating current to flow in the mandrel of an adjacent magnet. This current causes the coil wound on the mandrel to become normal through quench back. 


\section{Quench Propagation Velocity and the Hot Spot Temperature}

The quench process in a one-dimensional superconductor can be characterized by the following one-dimensional equation [3]:

$$
C \frac{\partial T}{\partial t}=\square j^{2}+\frac{\partial}{\partial x} \prod_{k} \frac{\partial T}{\partial x}[
$$

where $\mathrm{C}$ is the specific heat per unit volume $\left(\mathrm{J} \mathrm{m}^{-3} \mathrm{~K}^{-1}\right)$; $\mathrm{T}$ is temperature $(\mathrm{K})$; $\mathrm{t}$ is time (s); $\square$ is the electrical resistivity of the wire $(\square \mathrm{m})$; $\mathrm{j}$ is the current density in the wire $\left(\mathrm{A} \mathrm{m}^{-2}\right)$; $\mathrm{x}$ is the dimension along the wire $(\mathrm{m})$; and $\mathrm{k}$ is the wire thermal conductivity $\left(\mathrm{W} \mathrm{m}^{-1} \mathrm{~K}^{-1}\right)$. $\mathrm{C}, \mathrm{r}$, and $\mathrm{k}$ are nonlinear functions of the wire temperature. Equation 1 can be rearranged into the form;

$$
\frac{\partial F}{\partial T}=j^{2}+\frac{1}{\square} \frac{\partial}{\partial x} \underset{\theta}{Q} \square \frac{\partial F}{\partial x}[
$$

where $\mathrm{F}$ is defined as follows;

$$
F(T)=\square_{0}^{T} \frac{C}{\square} d T
$$

and $\square$ the thermal diffusivity is;

$$
\square=\frac{k}{C} .
$$

Equation 2 is non-linear and hence is difficult to solve in a meaningful way. The quench can be divided into three distinct regions. The first region (Region A) is characterized by a low thermal diffusivity. When $\square$ is neglected, equation 2 takes the following form;

$$
\frac{\partial F}{\partial t} \square j^{2}
$$

This is the equation used to calculate the burnout (hot spot temperature) of a superconducting magnet that was described by Tollestrup in the early 1970s [4], and Eberhard et al later [5].

The second region (Region B) is dominated by heat transfer and it is a region where the electrical resistivity is constant. (The thermal conductivity $\mathrm{k}$ is proportional to the temperature $\mathrm{T}$, and the specific heat $\mathrm{C}$, which is small, is proportional to $\mathrm{T}^{\mathrm{n}}$, where $\mathrm{n}$ is between 2 and 3.) The differential equation for this region takes the following form;

$$
\frac{\partial F}{\partial T}=j^{2}+\frac{\partial}{\partial x} \text { 㽞 } \frac{\partial F}{\partial x} \mathrm{E}
$$


Equation 5 takes the form that is similar to the wave equation. From this equation, a characteristic quench velocity can be derived.

The third region (Region $\mathrm{C}$ ) is the superconducting region characterized by zero resisitivity. This region does not enter into the discussions of this paper. The boundary between regions $\mathrm{A}$ and $\mathrm{B}$ occurs at temperatures between 15 and $30 \mathrm{~K}$. The boundary between regions $\mathrm{B}$ and $\mathrm{C}$ occurs at the transition temperature of the superconductor. This superconductor transition temperature is a function of the current density in the superconductor $\mathrm{j}$ and the magnetic induction $\mathrm{B}$ the conductor sees.

\section{a) The Velocity of Quench Propagation Waves along the Conductor}

The velocity of normal region propagation can be found from equation 5 . The solution to this equation takes the following general form [6];

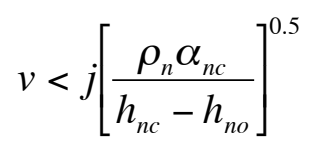

where $\square_{\mathrm{n}}$ is the resistivity of the normal metal; $\square_{\mathrm{nc}}$ is the thermal diffusivity of the normal metal at the superconductor critical temperature $\mathrm{T}_{\mathrm{c}}$; and $\left(\mathrm{h}_{\mathrm{nc}}-\mathrm{h}_{\mathrm{no}}\right)$ is the change in volume enthalpy from the superconductor operating temperature $T_{o}$ and $T_{c}\left(\mathrm{~J} \mathrm{~m}^{-3}\right)$.

Since the specific heat per unit volume is close to that of the normal metal, the thermal diffusivity and electrical resistivity of the normal metal plus superconductor take the following form;

$$
\begin{aligned}
& \square_{o}=\square_{n} \frac{r+1}{r} \\
& \text { and } \\
& \square_{o c}=\frac{k_{n c}}{C_{n c}} \frac{r}{r+1}
\end{aligned}
$$$$
-7-
$$

where $r$ is the ratio of the normal metal to the superconductor in the overall conductor. One can modify the equation 6 to the following form;

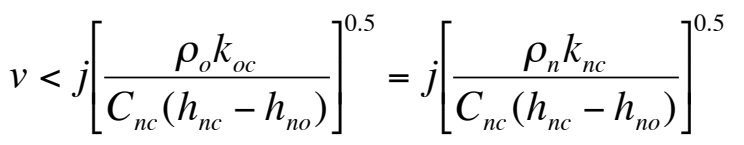

Note that equation 8 is completely independent of $r$. If one applies the Wiedemann Franz relationship where $\square(\mathrm{T}) \mathrm{k}(\mathrm{T})=\mathrm{LT}\left(\mathrm{L}\right.$ is the Lorenz number $\left(\mathrm{L}=2.45 \times 10^{-8} \mathrm{~W} \square \mathrm{K}^{-2}\right)$ ) at $\mathrm{T}_{\mathrm{c}}$, equation 8 will take the following form;

$$
v<j \frac{L T_{c}}{C_{n c}\left(h_{n c} \square h_{n o}\right)} \stackrel{0}{\square} .5
$$

From equation 9 is clear that the normal metal thermal conductivity and electrical resistivity have almost no effect on the normal region propagation velocity. 
If compares equation 9 with measurements of quench propagation velocity in magnets, the equation changes slightly. Based on LBNL quench propagation measurements made in the late 1970's on might use the following form for the equation;

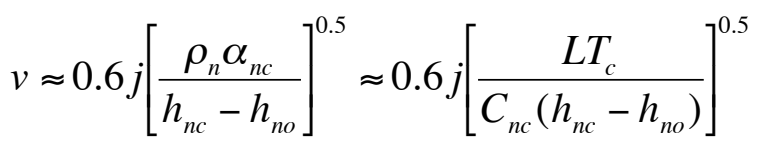

Equation 10 is dependent only on the current density in the conductor cross-section $\mathrm{j}$ and magnetic induction $\mathrm{B}$ the conductor sees. The dependence on matrix current density is about $\mathrm{j}^{1.5}$ at low current densities. At high current densities, where heat transfer from the conductor plays a negligible role, the matrix current density dependence is more like $\mathrm{j}^{2}$ as observed by Scherer and Turowski [7]. (See Figure 1.) At matrix current densities in the range of that for the MICE magnets the dependence is more like $\mathrm{j}^{1.65}$.

The following equation fits the potted coil experimental quench velocity points that are shown in Figures 1 and 2 from $\mathrm{j}=10^{8} \mathrm{~A} \mathrm{~m}^{-2}$ to $\mathrm{j}=4 \times 10^{8} \mathrm{~A} \mathrm{~m}^{-2}$ [8];

$$
v \square\left(5.7 \times 10^{\square 14}\right)(1+B)^{0.62} j^{1.65}
$$

where $\mathrm{B}$ is the magnetic induction at the wire $(\mathrm{T})$ and $\mathrm{j}$ is the current density across the conductor $\left(\mathrm{Am}^{-2}\right)$. The quench velocity measurements shown in Figure 1 were made in a potted magnet with the conductor at a magnetic induction of about $1.1 \mathrm{~T}$.

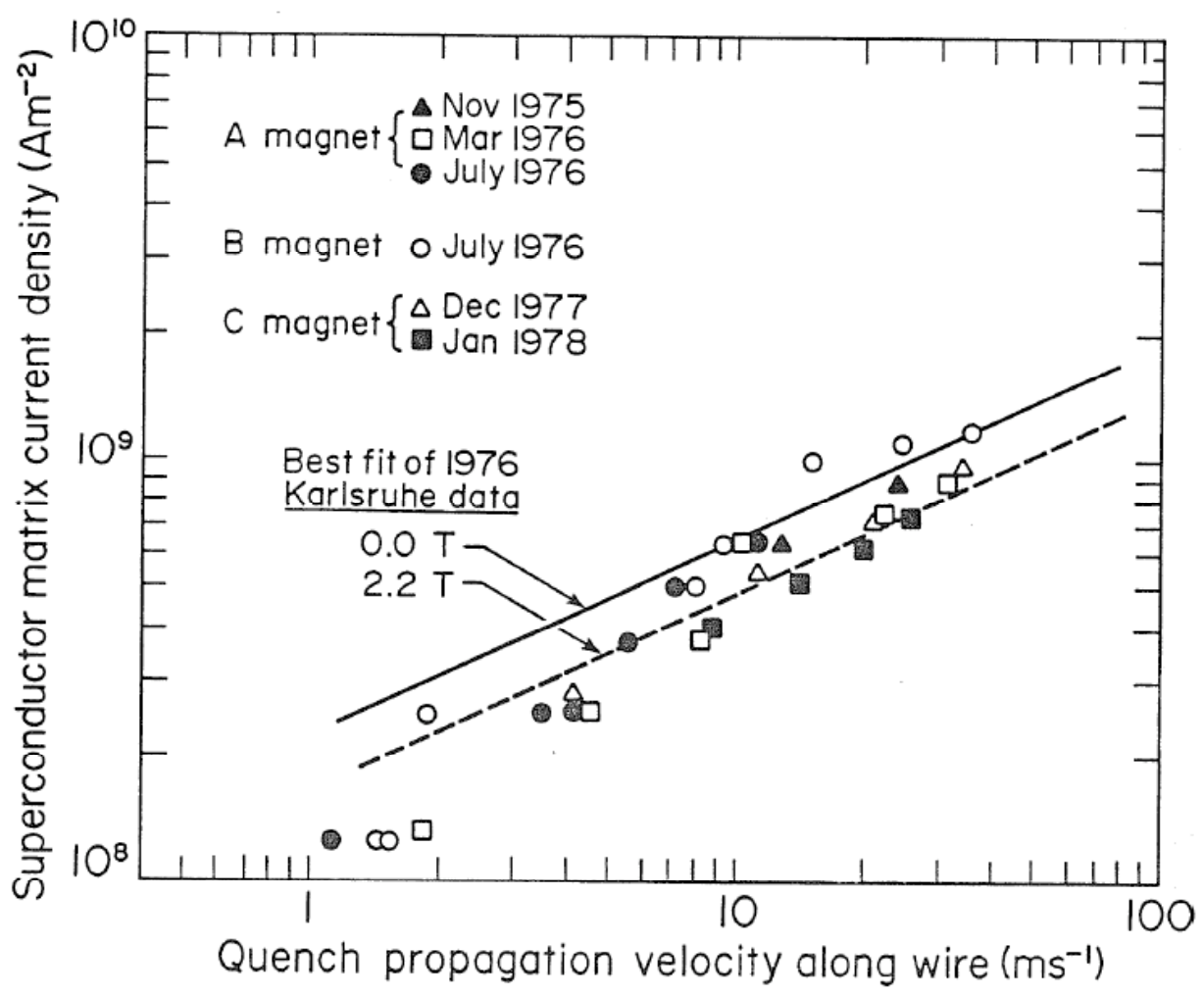

Figure 1. Measured LBNL Normal Region Propagation Velocities along the Superconducting Wire within a Potted Superconducting Magnet as a Function of the Overall Conductor Current Density.

The 1976 Kerforshugzentrum Karlsruhe data is plotted for comparison [7]. 


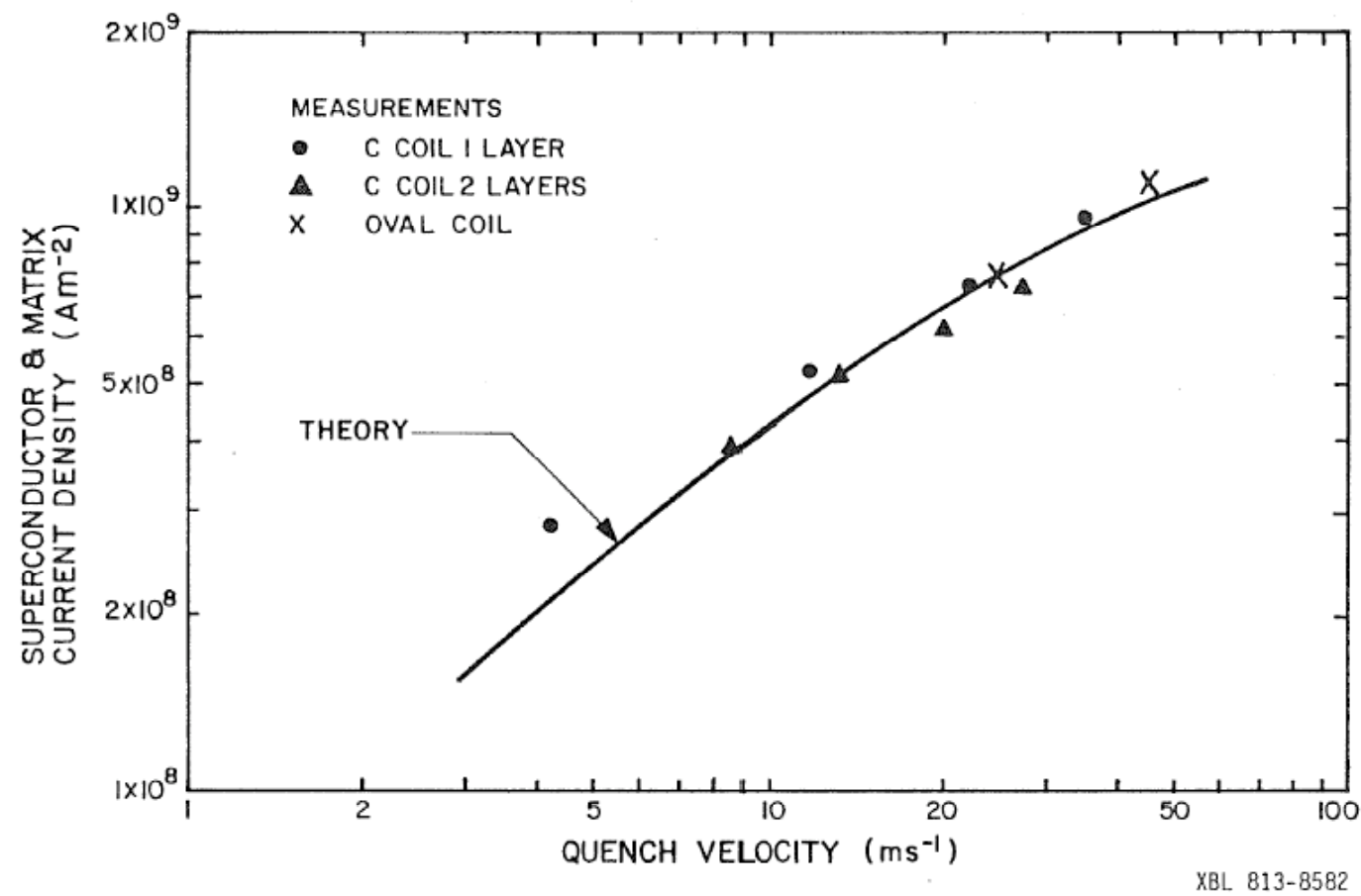

Figure 2. Predicted and Measured Quench Propagation Velocities along the Wire as a Function of the Conductor Overall Current Density [8]

Equation 11 applies for quench propagation velocity along the superconducting wire (in the $\square$ direction in a solenoid). On can also estimate the quench propagation velocity in the other two directions using the following relationships;

$$
v_{R}=\square v_{\square},
$$

and

$$
v_{Z}=\square v_{\square}
$$

$v_{\square}$ is the velocity around the solenoid (in the direction of the wire); $v_{R}$ is the quench velocity in the radial direction in the solenoid; and $\mathrm{v}_{\mathrm{Z}}$ is the quench velocity along the length of the solenoid. The dimensionless function $\square=\mathrm{v}_{\mathrm{R}} / \mathrm{v}_{\square}$, and the dimensionless function $\square=\mathrm{v}_{\mathrm{Z}} / \mathrm{v}_{\square}$.

The values of $\square$ and $\square$ depend on the dimensions of the bare conductor and the thickness of the insulation between layers (for $\square$ ) and between turns (for $\square$ ). The equations for calculating $\square$ and $\square$ for the MICE solenoid coils are as follows [9];

$$
\square \square 0.7 \stackrel{\square}{\square_{n} k_{i}} \frac{b}{S} \frac{r+1 \square^{0.5}}{r},
$$

and

$$
\square \square 0.7 \frac{\square}{=L T_{c}} \frac{k_{i}}{S} \frac{a}{r+1} \stackrel{r}{\square} .
$$


In equations $13 \mathrm{a}$ and $13 \mathrm{~b}, \mathrm{~L}$ is the Lorentz number $\left(\mathrm{L}=2.45 \times 10^{-8} \square \mathrm{WK}^{-2}.\right) ; \mathrm{k}_{\mathrm{i}}$ is the thermal conductivity of the insulation material (For a potted magnet, $\mathrm{k}_{\mathrm{i}}=0.04 \mathrm{Wm}^{-1} \mathrm{~K}^{-1}$.); $\mathrm{T}_{\mathrm{c}}$ is the conductor critical temperature (use $7 \mathrm{~K}$ ); and $\square_{\mathrm{n}}$ is the resistivity of the matrix metal. (For copper, $\square_{\mathrm{n}}=1.55 \times 10^{-8} / \mathrm{RRR}$ in $\square \mathrm{m}$.) (Note: RRR is the ratio of the normal metal resistivity at $273 \mathrm{~K}$ to the normal metal resistivity at $4 \mathrm{~K}$.) The values of $\square$ and $\square$ are inversely proportional to the square root of RRR. $\mathrm{S}$ is the insulation thickness; $\mathrm{a}$ is the length of the conductor (in the $\mathrm{z}$ direction); $\mathrm{b}$ is the thickness of the conductor (in the $\mathrm{r}$ direction); and $\mathrm{r}$ is the copper to superconductor ratio.

In general, $\square$ and $\square$ will have a value of 0.012 to 0.05 for a typical niobium titanium magnet with a copper conductor with RRR from 20 to 140 . From equation 9, it is clear that RRR has almost no effect on the quench velocity along the wire. For the MICE coupling magnet and focusing magnet, which use a bare conductor than is $0.95 \mathrm{~mm}$ by $1.60 \mathrm{~mm}$ with rounded ends, the values are:

$$
\begin{gathered}
\text { r direction } \\
\mathrm{S}=0.105 \mathrm{~mm} \\
\square_{\mathrm{n}}=1.55 \times 10^{-10} \square \mathrm{m} \\
\mathrm{a}=0.95 \mathrm{~mm} \\
\mathrm{r}=4 \\
\square=0.0142
\end{gathered}
$$

z direction
$\mathrm{S}=0.08$
$\square_{\mathrm{n}}=1.55 \times 10^{-10} \square \mathrm{m}$
$\mathrm{b}=1.6 \mathrm{~mm}$
$\mathrm{r}=4$
$\square=0.0214$

The conductor proposed for the MICE magnets will have a design RRR $=100$. Reducing the RRR will increase the quench propagation velocity in the $\mathrm{r}$ and $\mathrm{z}$ directions (by increasing $\square$ and $\square$ ) without changing the propagation velocity in the $\square$ direction, but there are some negative implications that make this undesirable. The reasons for wanting to keep the matrix material RRR high are as follows: 1) Having a matrix RRR that is high improve the stability of the superconductor, particularly if the superconducting filaments are large. 2) Having the matrix RRR high reduces the voltage buildup in the early part of the quench. (At the end of the quench, RRR has little effect on the voltages within the coil.) 3) Reducing the RRR of the matrix material will reduce the integral of $j^{2} \mathrm{dt}$ needed to reach the maximum allowable coil hot spot temperature. The improved quench propagation within the coil may end up being of little or no advantage overall.

The values of $\square$ and $\square$ given above for the MICE coils are conservative in the high field regions of the coil because magneto resistance will increase the resistivity of the matrix material by a factor of two in the high field regions of both coils. The value of $T_{c}$ will also be reduced. Both effects will increase the values of $\square$ and $\square$ in the high field regions of the MICE coils by about 50 percent. Because $\square$ and $\square$ are lower in the low field regions of the coil the use of the values given above would be prudent.

\section{b) The Derivation of the Conductor Burnout Condition}

The conductor burn out condition (maximum hot spot temperature) is a function of the properties of the conductor for a given value of the integral of $j^{2} \mathrm{dt}$. When one designs the magnet quench protection system, limiting the maximum hot spot temperature is the most important part of the quench protection system design.

The limit for the burnout condition for a superconducting magnet is derived by integrating equation 4; 


$$
F=\bigsqcup_{0}^{t} j^{2} d t
$$

Redefining this equation slightly from the basic definition for $\mathrm{F}$ given by equation $3 \mathrm{a}$, one gets the following expression;

$$
F *(T)=\square_{0}^{T} C(T) d T=\frac{r+1}{r} \bigsqcup_{0}^{t} j^{2} d t .
$$

When a magnet quenches the start for the quench is $t=0$. The end at time for the magnet quench is when the current in the coil has completely decayed away $\mathrm{t}=$. Using the quench time limits, the equation for $\mathrm{F}^{*}(\mathrm{~T})$ takes the following form;

$$
F *\left(T_{M}\right)=\prod_{0}^{T_{M}} \frac{C(T)}{\square(T)} d T=\frac{r+1}{r} \square_{0} j^{2} d t=\frac{r+1}{r} J_{0}^{2} \square_{0}^{\square}(t)^{2} d t
$$

The temperature $T_{M}$ is the maximum hot spot temperature in the coil. $\mathrm{J}_{0}$ is the starting current density in conductor cross-section and $\square(\mathrm{t})$ is the decay function for the current in the magnet with time $(\square(0)=1 ; \square(\quad)=0)$ Thus, if one defines the permissible maximum hot spot temperature $T_{M}$, one defines a permissible integral for $j^{2} d t$.

Figure 3 Shows $\mathrm{F}^{*}(\mathrm{~T})$ as a function of temperature $\mathrm{T}$ and the matrix material RRR. Figure 3 shows this for both copper matrix conductors and aluminum matrix conductor. The lower values of $\mathrm{F}^{*}(\mathrm{~T})$ for aluminum conductors reflect the lower volume specific heat and higher resistivity for the matrix at a given RRR.

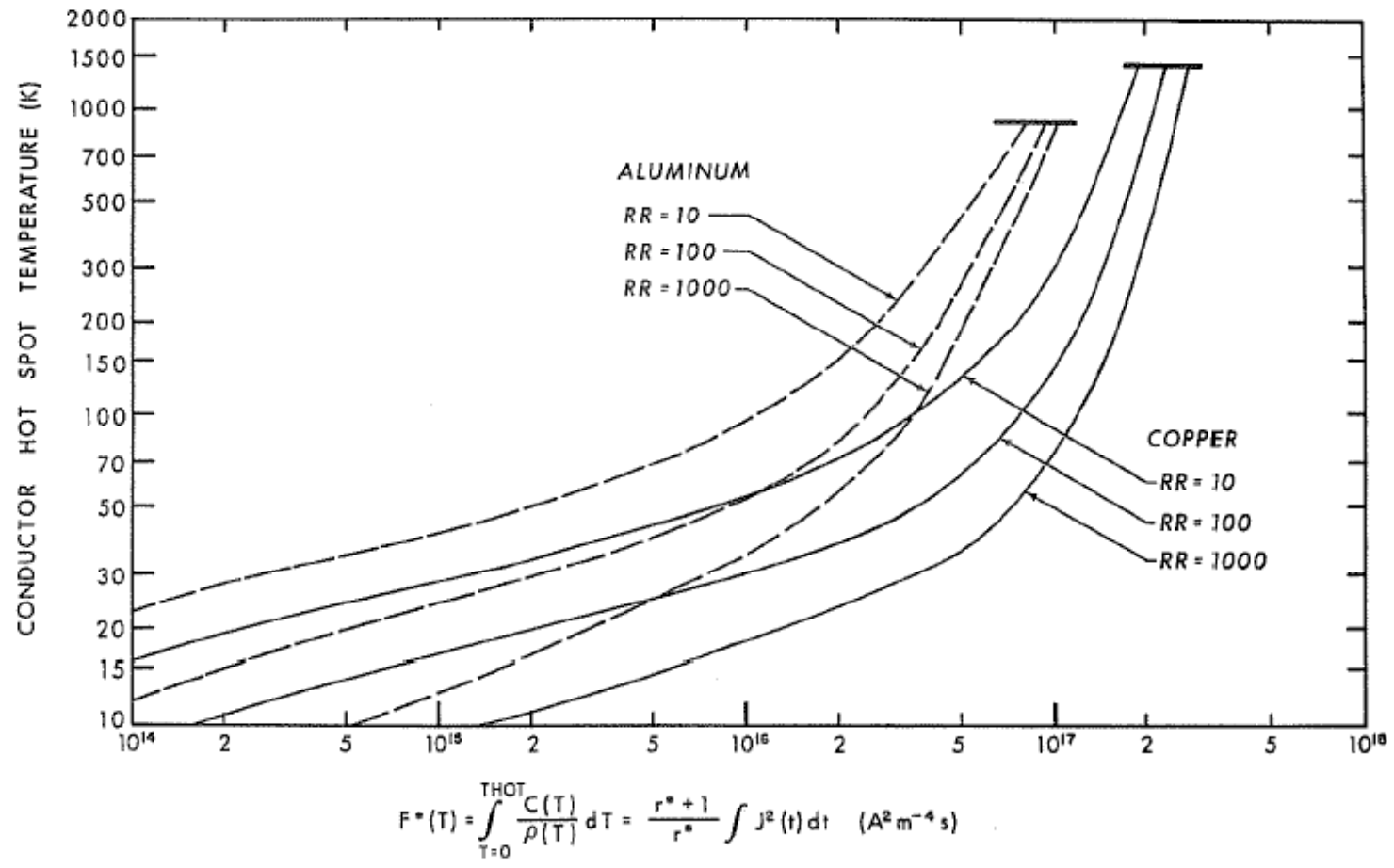

XBL $774-8481$

Figure 3. Hot Spot Temperature $T_{M}$ versus $F^{*}(T)$ for Copper and Aluminum with Various RRR Values 


\section{Active Quench Protection using a Resistor}

When a constant resistance $R_{c}$ is put across the leads of a superconducting magnet with an inductance of $\mathrm{L}_{1}$, there is an exponential decay of the current density in the wire cross-section, which takes the following form;

$$
j(t)=j_{o} e^{\square \frac{t}{\square_{1}}}
$$

where $j_{o}$ is the current density in the conductor at time $t=0 ; t$ is time; and $\square$ is the $L_{1} / R_{o}$ time constant for the magnet circuit. $\mathrm{L}_{1}$ is the self-inductance of the magnet circuit and $R_{o}$ is the resistance put across the magnet leads. Figure 4 shows the magnet circuit before and after the quench protection resistor has been put across the magnet leads.

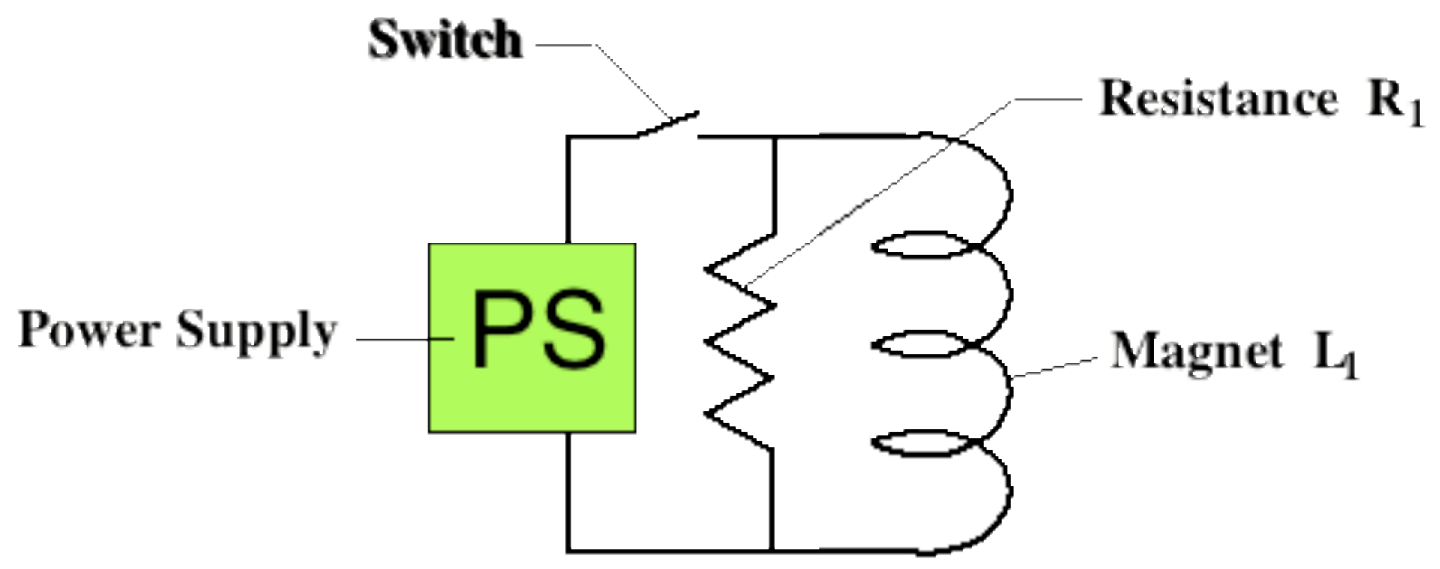

Figure 4. Quench Protection by putting a Resistor across the Magnet Leads

If one integrates $\mathrm{j}^{2} \mathrm{dt}$ from equation 16 , one gets the following expression for $\mathrm{F}^{*}(\mathrm{~T})$;

$$
F *\left(T_{M}\right)=\frac{L_{1}}{2 R_{1}} \frac{r+1}{r} j_{o}^{2}
$$

One can rearrange equation 18 to get the resistance $\mathrm{R}_{1}$ across the leads needed to produce a given value of $\mathrm{F}^{*}(\mathrm{~T})$ for a given maximum hot spot temperature $\mathrm{T}_{\mathrm{M}}$. This expression for this resistance is;

$$
R_{1}=\frac{L}{2 F^{*}\left(T_{M}\right)} \frac{r+1}{r} j_{o}^{2}
$$

Thus, one can find the $L / R$ time constant $t$ needed to produce a given value of $F^{*}\left(T_{M}\right)$. The expression for the current decay time constant as a function of $F^{*}\left(T_{M}\right)$ and $j_{o}$ is given as follows;

$$
\square_{1}=\frac{L_{1}}{R_{o}}=\frac{2 F^{*}\left(T_{M}\right)}{j_{o}^{2}} \frac{r}{r+1}
$$


The maximum voltage $\mathrm{V}_{\mathrm{o}}$ across the leads of the magnet needed to limit the quench maximum hot spot temperature to $\mathrm{T}_{\mathrm{M}}$ can be calculated using the following expression;

$$
V_{o}=i_{o} R_{o}=\frac{A_{c} L}{2 F^{*}\left(T_{M}\right)} \frac{r+1}{r} j_{o}^{3}
$$

From equations 20 and 21 one can derive the well known $\mathrm{Ej}^{2}$ limit for quenching, which takes the following form;

$$
E_{o} j_{o}^{2}=F *\left(T_{M}\right) V_{o} i_{o} \frac{r}{r+1}
$$

where $E_{o}$ is the fully charged stored energy of the magnet (at the start of the quench); $j_{o}$ is the current density across the conductor cross-section (copper plus superconductor); and $\mathrm{F}^{*}\left(\mathrm{~T}_{\mathrm{M}}\right)$ is the $\mathrm{F}^{*}$ function for the maximum hot spot temperature $\mathrm{T}_{\mathrm{M}}$. The quench $\mathrm{Ej}^{2}$ function is proportional to $\mathrm{F}^{*}\left(\mathrm{~T}_{\mathrm{M}}\right)$, the maximum discharge voltage $\mathrm{V}_{\mathrm{o}}$ and the starting current $\mathrm{I}_{\mathrm{o}}$.

Table 1 shows the quench characteristics for the MICE focusing magnet. Table 1 shows the quench parameters for a single focusing magnet hooked up in the gradient (flip) mode and in the solenoid (non-flip) mode. Table 1 also shows the quench parameters for three focusing magnets hooked in series both in the flip mode and in the non-flip mode. The Table 1 currents are for the $\mathrm{p}=240 \mathrm{MeV} / \mathrm{c} \square=450 \mathrm{~mm}$ cases for the two modes. Table 2 shows the quench characteristics for a single coupling magnet and for two coupling magnets hooked in series. Table 2 shows the quench parameters at the operating currents when the $\mathrm{p}=240 \mathrm{MeV} / \mathrm{c} \square=450 \mathrm{~mm}$ and with MICE operating in the flip mode and the non-flip mode. The conductor for both magnets has an $\mathrm{r}=4$ and a cross-section area $A_{c}=1.38 \mathrm{~mm}^{2} . F^{*}\left(T_{M}\right)=1.5 \times 10^{17} \mathrm{~A}^{2} \mathrm{~m}^{-4} \mathrm{~s}$ when $\mathrm{T}_{\mathrm{M}}=400 \mathrm{~K}$.

\begin{tabular}{|c|c|c|c|c|}
\hline \multirow{2}{*}{ Quench Parameter } & \multicolumn{2}{|c|}{ Single Magnet } & \multicolumn{2}{|c|}{ Three Magnets } \\
\hline & Flip & Non-Flip & Flip & Non-Flip \\
\hline Design Operating Current (A) & 250.7 & 130.5 & 250.7 & 130.5 \\
\hline Conductor Current Density $\left(\mathrm{A} \mathrm{mm}^{-2}\right)$ & 181.7 & 94.6 & 181.7 & 94.6 \\
\hline Magnet System Inductance (H) & 98.6 & 137.4 & 293 & 420 \\
\hline Magnet System Stored Energy (MJ) & 3.10 & 1.17 & 9.21 & 3.58 \\
\hline Protection Resistor Resistance $(\square)$ & 13.5 & 5.12 & 40.0 & 15.7 \\
\hline Peak Protection Voltage (V) & 3374 & 668 & 10053 & 2049 \\
\hline Magnet Discharge Time Constant (s) & 7.33 & 26.8 & 7.33 & 26.8 \\
\hline Magnet System $\mathrm{E}_{\mathrm{o}} \mathrm{j}_{\mathrm{o}}^{2}\left(\mathrm{~J} \mathrm{~A}^{2} \mathrm{~m}^{-4}\right)$ & $1.02 \times 10^{23}$ & $1.05 \times 10^{22}$ & $3.04 \times 10^{23}$ & $3.20 \times 10^{22}$ \\
\hline
\end{tabular}

Table 1. The Quench Characteristics of the MICE Focusing Magnets operating in Various Modes 
Table 2. The Quench Characteristics of the MICE Coupling Magnets operating in Various Modes

\begin{tabular}{|c|c|c|c|c|}
\hline \multirow{2}{*}{ Quench Parameter } & \multicolumn{2}{|c|}{ Single Magnet } & \multicolumn{2}{|c|}{ Two Magnets } \\
\hline & Flip & Non-Flip & Flip & Non-Flip \\
\hline Design Operating Current (A) & 213.2 & 206.3 & 213.2 & 206.3 \\
\hline Conductor Current Density $\left(\mathrm{A} \mathrm{mm}^{-2}\right)$ & 154.5 & 149.5 & 154.5 & 149.5 \\
\hline Magnet System Inductance (H) & 563 & 563 & 1108 & 1154 \\
\hline Magnet System Stored Energy (MJ) & 12.8 & 12.0 & 25.2 & 24.6 \\
\hline Protection Resistor Resistance $(\square)$ & 55.8 & 52.4 & 109.9 & 107.4 \\
\hline Peak Protection Voltage (V) & 11897 & 10810 & 23431 & 22157 \\
\hline Magnet Discharge Time Constant (s) & 10.09 & 10.74 & 10.09 & 10.74 \\
\hline Magnet System $\mathrm{E}_{\mathrm{o}} \mathrm{j}_{\mathrm{o}}^{2}\left(\mathrm{~J} \mathrm{~A}^{2} \mathrm{~m}^{-4}\right)$ & $3.06 \times 10^{23}$ & $2.68 \times 10^{23}$ & $6.04 \times 10^{23}$ & $5.49 \times 10^{23}$ \\
\hline
\end{tabular}

Equation 22 shows that if one wants to limit the discharge voltage during a quench, one must increase the magnet current for a given $\mathrm{F}^{*}\left(\mathrm{~T}_{\mathrm{M}}\right)$. Large currents are commonly used in accelerator magnets and large detector magnets as a means to make the quench protection process in these magnets doable.

Tables 1 and 2 show high peak voltages across the magnet leads are needed, when an external resistor is used to protect the focusing or the coupling coils. This is true whether these coils are protected as a single coil or as a number of coils in series. Even with high quench protection voltages, the quench time constants are quite large (from 7 to 10 seconds). Using a varistor resistor (solid-state resistor where the voltage across the resistor is kept constant as the current goes down in place of a standard resistor will reduce the quench protection peak voltages, but the reduction of the quench protection voltages is not really enough to make this option attractive [5].

In the MICE magnets, increasing the magnet current is not an option for reducing the quench protection voltages. The reason that the magnet current cannot be increased is that the magnets will be cooled using small coolers. Large MICE magnet currents result in larger heat flows into the first and second stages of the coolers. Since one cannot increase the current in the MICE magnets, quench protection using a resistor across the leads is not the best quench protection method for any of the MICE magnets.

Since one cannot just depend on a resistor across the leads to protect the MICE magnets. One must put as much of the magnet stored-energy into the magnet windings as one can. First, this means that one must understand the quench propagation process in the MICE coils. In the case of the MICE coils, the lengths of the coils are relatively short compared to their diameter, so the quench propagation within the coil becomes important. Second, the coils must be driven normal from the mandrel through quench back. Quench back is particularly important when the coils are part of a single series circuit.

The next section will describe the process of quench propagation in the coils and how this quench propagation will induce quench back between the mandrel and the coil. The quench back process will cause other coils in the string to go normal. As a result, it is possible to put a number of the focusing coils and coupling coils in series. 


\section{Quench Propagation in the Magnet Coils}

Equations $11,12 \mathrm{a}$ and $12 \mathrm{~b}$ show the quench propagation velocities $\mathrm{v}_{\square}, \mathrm{v}_{\mathrm{R}}$, and $\mathrm{v}_{\mathrm{Z}}$ within the magnet coils. Using these equations one can estimate the amount of time needed to drive the entire coil normal $\mathrm{t}_{\mathrm{MAG}}$. The time needed to drive the entire coil normal should be evaluated for the average magnetic induction within the coil. For both the focusing and the coupling coil the average induction in the coil is about $2.5 \mathrm{~T}$. If one uses the average magnetic induction in the coil, the calculated time for the coil to go completely normal is probably conservative. The quench in most likely initiated at the high field point on the inner surface of the coil. At or near the high field point, the quench velocities are large. The quench will propagate around the coil and along the coil (in the $\mathrm{z}$ direction) rapidly. As the quench moves outward (in the $\mathrm{r}$ direction), it will slow down as the field decreases; then it will speed up as the field increases.

The value of $\mathrm{t}_{\mathrm{MAG}}$ can be calculated using the following expression;

$$
t_{M A G}=t_{\square}+t_{R}+t_{Z}
$$

where the average value of $t_{\square}$ and $t_{R}$ are;

$$
\begin{aligned}
& t_{\square}=\frac{\square R_{c}}{v_{\square}}=\frac{\left(1.75 \times 10^{13}\right) \square R_{c}}{\left(1+B_{\text {ave }}\right)^{0.62} j^{1.65},} \\
& t_{R}=\frac{T_{c}}{v_{R}}=\frac{\left(1.75 \times 10^{13}\right) T_{c}}{\square\left(1+B_{\text {ave }}\right)^{0.62} j^{1.65}},
\end{aligned}
$$

and the maximum value of $\mathrm{t}_{\mathrm{z}}$ (based on the quench starting in the corner) is;

$$
t_{Z}=\frac{L_{c}}{v_{Z}}=\frac{\left(1.75 \times 10^{13}\right) L_{c}}{\square\left(1+B_{\text {ave }}\right)^{0.62} j^{1.65}},
$$

where $B_{\text {ave }}$ is the average magnetic induction in the coil; $R_{c}$ is the average radius of the coil; $\mathrm{T}_{\mathrm{c}}$ is the thickness of the coil; and $\mathrm{L}_{\mathrm{c}}$ is the length of the coil. (Note: setting $\mathrm{L}_{\mathrm{c}}$ as the length of the coil instead of the half-length of the coil makes equation 23 even more conservative in terms of estimating the time needed for all of the coil to go normal. The values of $\square$ and $\square$ are defined by equations $13 \mathrm{a}$ and $13 \mathrm{~b}$.

For the superconductor and insulation selected for both the focusing coils and the coupling coils, $\square=0.0142, \square=0.0214$, and $\mathrm{B}_{\text {ave }}=2.5 \mathrm{~T}$. For the focusing magnet, the value of $\mathrm{j}$ that one should use is $\mathrm{j}=1.81 \times 10^{8} \mathrm{~A} \mathrm{~m}^{-2}$. For the coupling magnet, the value of $\mathrm{j}$ that one should use is $\mathrm{j}=1.54 \times 10^{8} \mathrm{~A} \mathrm{~m}^{-2}$. Using Equation 11, one can see that the average quench velocity along the wire for a fully charged focusing magnet in the flip mode is about $5.2 \mathrm{~m} \mathrm{~s}^{-1}$. For a fully charged coupling magnet in the flip mode, the average quench velocity along the wire is about $4.0 \mathrm{~m} \mathrm{~s}^{-1}$.

Table 3 shows the values of $R_{c}, T_{c}$, and $L_{c}$ for the focusing and coupling coils. From these values the quench propagation time $t_{\square}, t_{R}$, and $t_{Z}$ are calculated. Table 3 presents the calculated time for the coil to become fully normal $t_{\mathrm{MAG}}$. This time is compared with the magnet discharge time constant $\square$ (see Equation 20) shown in Tables 1 and 2. 
Table 3. Coil Dimensions, and Quench Propagation Times for the Focusing and Coupling coils The total quench propagation time within the coils is compared with magnet discharge time constant.

\begin{tabular}{|l|c|c|}
\hline \multicolumn{1}{|c|}{ Quench Parameter } & Focusing & Coupling \\
\hline Quench Velocity along the Wire $\left(\mathrm{m} \mathrm{s}^{-1}\right)$ & $\mathbf{5 . 2}$ & $\mathbf{4 . 0}$ \\
\hline Coil Average Half Circumference $(\mathrm{m})$ & $\mathbf{0 . 9 5 8}$ & $\mathbf{2 . 4 5}$ \\
\hline Coil Thickness $\mathrm{T}_{\mathrm{c}}(\mathrm{m})$ & $\mathbf{0 . 0 8 4}$ & $\mathbf{0 . 1 1 6}$ \\
\hline Coil Length $\mathrm{L}_{\mathrm{c}}(\mathrm{m})$ & $\mathbf{0 . 2 1 0}$ & $\mathbf{0 . 2 5 0}$ \\
\hline Time to Propagate Quench around Coil $(\mathrm{s})$ & $\mathbf{0 . 1 8}$ & $\mathbf{0 . 6 1}$ \\
\hline Time to Propagate Quench along $\mathrm{T}_{\mathrm{c}}(\mathrm{s})$ & $\mathbf{1 . 1 4}$ & $\mathbf{2 . 0 4}$ \\
\hline Maximum Time to Propagate Quench along $\mathrm{L}_{\mathrm{c}}(\mathrm{s})$ & $\mathbf{1 . 8 9}$ & $\mathbf{2 . 9 2}$ \\
\hline Most Probable Time to Quench the Entire Coil $(\mathrm{s})$ & $\mathbf{2 . 2 7}$ & $\mathbf{4 . 1 1}$ \\
\hline Maximum Time to Quench the Entire Coil $(\mathrm{s})$ & $\mathbf{3 . 2 1}$ & $\mathbf{5 . 5 7}$ \\
\hline Safe Quench Discharge Time Constant $(\mathrm{s})$ & 7.33 & $\mathbf{1 0 . 0 9}$ \\
\hline
\end{tabular}

Table 3 shows that the calculated most probable time for the quench to propagate to all parts of the focusing coil and coupling coil is less than half of the magnet discharge time constant for safe quenching. The maximum calculated time for quench propagation within the coils is larger, but still safe. Once the whole coil has turned normal, the magnet stored-energy is dumped in the coil.

At an average coil temperature of $100 \mathrm{~K}$, the resistance of a single focusing coil will be about 41.6 ohms. This resistance is over three times the resistance needed to quench the magnet (both coils) safely. The conclusion that one draws from this is that the focusing magnet will probably quench safely without an external quench protection system even if only one of the two coils turns normal.

At an average coil temperature of $100 \mathrm{~K}$, the resistance of the coupling coil will be about 173.1 ohms. This resistance is also over three times the resistance needed to quench the magnet safely. The conclusion that one draws from this is that the coupling magnet will probably quench safely without and external quench protection system.

The high resistance of the coil at or near the end of the quench implies high voltages during the quench process. The current is low when the resistance is at its highest, so the voltages are not as high as one would think. The resistive voltages within the coil will be balanced by the inductive voltages within the coil. The net voltages to ground or across the magnet layers are in fact quite reasonable. It is always better to quench a magnet all at once, because the voltage buildup within the coil is minimized.

In both magnets, even the most probable calculated quench times are conservative. More of the conductor will be involved early in the quench process than is implied by the quench propagation time calculations. Two other factors come into play. First, the $\mathrm{L}_{\mathrm{c}}$ is about half of what was used in the quench time equation so the time for this part of the quench to take place will be half as much. Second, quench back from the mandrel will great speed up the quench propagation process in the coils. Because Quench back speeds up the quench process within the coil, it also reduces the voltage buildup within the coil. If the coils are designed with a layer-to-layer voltage of $>500 \mathrm{~V}$ and a voltage to ground of $>3000 \mathrm{~V}$, there should be no trouble during a magnet quench.

Quench back will also have the effect of quenching the second coil in the case of the focusing magnet. Quench back will permit the three focusing magnets to be hooked in series and it will also permit the two coupling magnets to be hooked in series. 


\section{Coil Quench Back from the Aluminum Mandrel}

Quench back implies that there is a current flowing in the magnet mandrel during the quench process. The mandrel behaves as a shorted secondary circuit that is inductively well coupled with the magnet (the primary circuit). Figure 5 shows the magnet with its coupled secondary circuit (the mandrel). The only way that a current can flow in the magnet mandrel is that the mandrel is inductively coupled with the magnet coil. In both the focusing and coupling magnets, the mandrel in a continuous cylinder of aluminum around the coil package. The coupling between the coils and the adjacent mandrel must be reasonably good in order for the current in the magnet to be effectively transferred to the magnet mandrel.

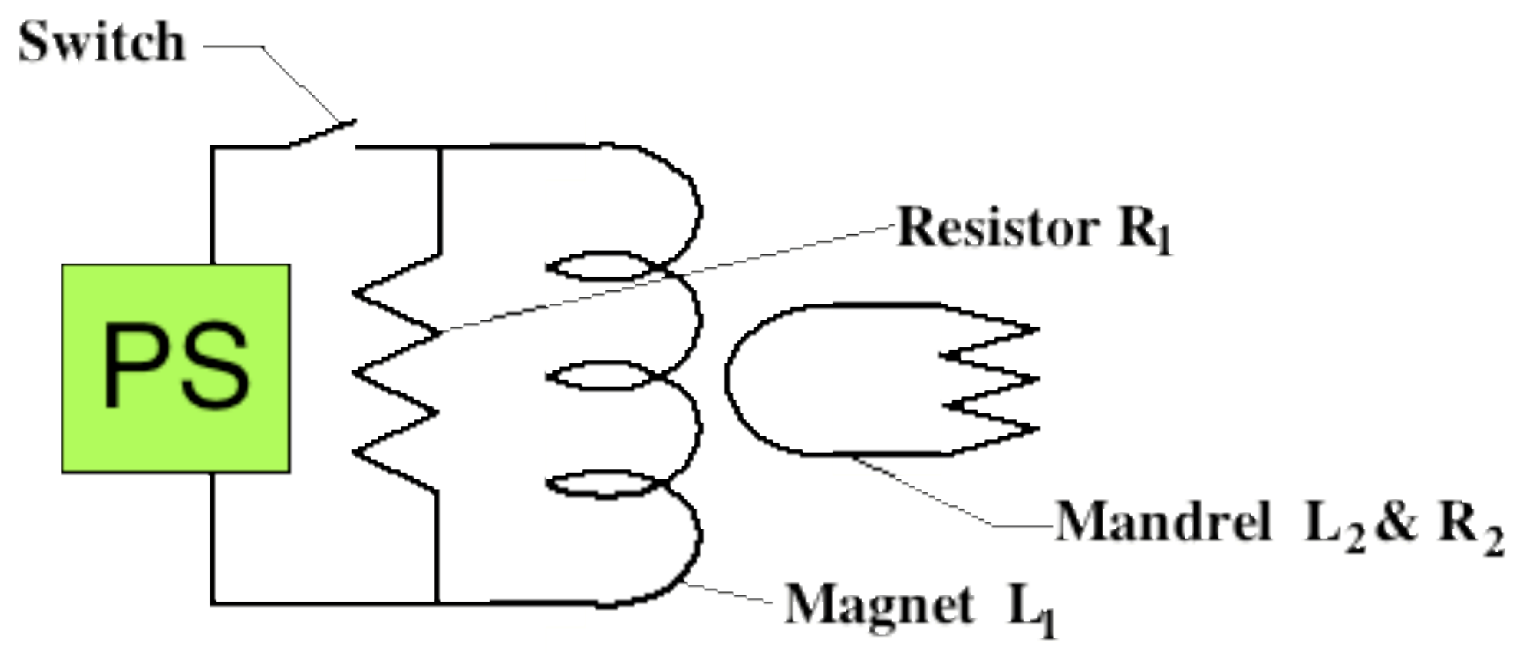

Figure 5. Quench Protection with a Resistor across the Magnet Leads and by having a Shorted Secondary Circuit coupled with the Primary Circuit

a) The Effect of the Mandrel as a Shorted Secondary Circuit

The effective coupling coefficient $\square$ between the focusing coils and their mandrel is estimated to be about 0.82 . The effective coupling coefficient $\square$ between the coupling coil and its mandrel is estimated to be about 0.92. The use of an effective coupling coefficient allows one to simplify the quench back problem to a simple circuit. As we will see later, the region of the mandrel that is closest to the coil will be coupled more closely with the than the use of an effective coupling coefficient suggests. This means that the quench back times derived from the use of an effective coupling coefficient will be longer than the actual quench back from the current carrying mandrel to the coil.

A well-coupled low resistance mandrel will affect the quench process in the following ways: 1) A mandrel behaves as a shorted secondary that causes current in the coil to shift to the mandrel. 2) The mandrel will absorb a substantial amount of the magnet stored-energy during the quench. The mandrel will end up at nearly the same temperature as the average temperature of the coil at the end of the quench. 3) Since the time constant for magnetic flux decay is long compared to the time constant for the initial current decay (for a well-coupled system), the transient voltages in the coil are reduced. 4) Since a portion of the current in the coil is transferred to the mandrel (for a wellcoupled system), the integral of $\mathrm{j}^{2} \mathrm{dt}$ is reduced, thus the hot spot temperature in the coil is 
reduced. 5) The mandrel heats up from the current flowing within it. This heating causes portions of the coil that are close to the mandrel to turn normal faster than they would from ordinary quench propagation. This phenomenon is called quench back.

When $\square$ the coil L over R time constant and $\square_{2}$ the mandrel L over R time constant, respectively, are constant, the current $\mathrm{i}$ in the coil has the following relationship;

$$
i=\frac{i_{0}}{\square_{L} \square \square_{S}} \stackrel{\square}{\square}\left(\square_{1} \square \square_{S}\right) e^{\frac{\square t}{\square_{L}}}+\left(\square_{L} \square \square_{1}\right)^{\frac{\square t}{\square_{s}}} \frac{[}{E} .
$$

When the coupling is good the coefficient $\square$ is small, where $\square$ is defined as follows;

$$
\square=[1 \square]]=\stackrel{\square}{\longrightarrow} \square \frac{M_{102}^{2}}{L_{1} L_{2}}[
$$

where $\square$ is the coupling coefficient between the coil and the mandrel; $\mathrm{L}_{1}$ is the selfinductance of the coil; $\mathrm{L}_{2}$ is the self-inductance of the mandrel; and $\mathrm{M}_{1-2}$ is the mutual inductance between the coil and the mandrel. (Note: for a perfectly coupled coil and mandrel $\mathrm{L}_{2}=\mathrm{L}_{1} / \mathrm{N}_{1}^{2}$ and $\mathrm{M}_{1-2}=\mathrm{L}_{1} / \mathrm{N}_{1}$ where $\mathrm{N}_{1}$ is the number of turns in the coil.)

With $\square<<1, \square$ and $\square$ take the following approximate form;

$$
\square_{L} \square \square_{1}+\square_{2}
$$

and

$$
\square_{S} \square \frac{\square_{1} \square_{2}}{\square_{1}+\square_{2}}
$$

When $\square_{l}$ and $\square_{2}$ are constant, the value of $F^{*}\left(T_{M}\right)$ takes the following approximate form (with no quench back assumed);

$$
F *\left(T_{M}\right)=\frac{r+1}{r} j_{0}^{2} \stackrel{\square}{-2\left(\square_{1}+\square_{2}\right)}+\frac{\square_{S}}{2}[-
$$

When on compares equation 28 with equation 18 , it is clear that the value of $F^{*}\left(T_{M}\right)$ is always lower when there are a conductive mandrel. When the time constant for the mandrel $\square_{2}$ is long compared to the coil circuit time constant $\square$, the reduction in $\mathrm{F}^{*}\left(\mathrm{~T}_{\mathrm{M}}\right)$ is quite large, even without quench back to the coil contributing to an additional reduction in the value of $\square$. The comparison between equations 28 and 18 explains how dramatic reductions in $\mathrm{F}^{*}$ are achievable within closely coupled large thin solenoids [10].

Within the MICE coupling and focusing solenoids $\square_{k}<\square_{1}$ (particularly early in the quench) because the mandrel is fabricated from a very high resistivity 6061-T6 aluminum $\left(\square=1.42 \times 10^{-8} \square \mathrm{m}\right.$ for RRR $\left.=1.8\right)$. The MICE focusing magnet has $\square_{2}=0.43 \mathrm{~s}$. The MICE coupling magnet has a $\square_{k}=0.40 \mathrm{~s}$. In order for the MICE magnet mandrel to significantly reduce $\mathrm{F}^{*}$ by itself (without quench back), the mandrel must be made from a low resistivity $1100-\mathrm{O}$ aluminum $\left(\square=8.3 \times 10^{-10} \square \mathrm{m}\right.$ for RRR $\left.=30\right)$. For $1100-\mathrm{O}$ aluminum $\square_{\mathrm{b}}$ for the focusing and coupling mandrels are $7.4 \mathrm{~s}$ and $6.8 \mathrm{~s}$ respectively. 
In the MICE magnets, $\mathrm{F}^{*}$ will not be reduced very much by the mandrel without quench back. Quench back from the mandrel to the coil can still be a factor in reducing $\mathrm{F}^{*}$ during a quench, even if the mandrel resistivity is high. Quench back become an important factor for reducing the $\mathrm{F}^{*}$ in any coil with a coupled-secondary circuit that is thermally connected to the coil (or coils) [11], [12].

\section{b) Quench Back in the Coil from the Mandrel}

The process of magnet quench back from a conducting mandrel is adequately discussed in Reference [9], [11], and [12], so this section of the report will no do much more than present the basic equations for the quench back process. In general, importance of quench back to the quench process of the MICE magnets is limited to reducing the hot spot temperature and the voltages that occur within the coil package. The hot spot temperature is reduced because the whole coil becomes fully normal in a time that is less than the time calculated using equation 23 . The voltages within the coil are lowered because the resistance of the coil is more evenly spread within the coil.

In order for quench back to be effective in improving the quench process within the magnet, the time for quench back to start $\mathrm{t}_{\mathrm{QBS}}$ must be substantially less than the time that the whole coil would turn normal on its own without quench back $t_{\mathrm{MAG}}$. The question is, "What is substantially shorter time for quench back?" One answer to the question is that $t_{\mathrm{QBS}}<\mathrm{t}_{\mathrm{MAG}}-\mathrm{t}_{\mathrm{Z}} / 2$. Since $\mathrm{t}_{\mathrm{Z}}$ is the longest of the three times in equation 23, a much better answer is that $t_{\mathrm{QBS}}<\left(\mathrm{t}_{\square}+\mathrm{t}_{\mathrm{R}}\right)$ (See equations 24a and 24b). The authors suggest a shorter time $t_{\mathrm{QBS}}=\left(\mathrm{t}_{\square}+\mathrm{t}_{\mathrm{R}}\right) / 2$.

Once a value for $\mathrm{t}_{\mathrm{QBS}}$ has been settled on, one can look at the minimum external resistance $\mathrm{R}_{\mathrm{ex}}$ in the coil circuit that will induce quench back from the mandrel in the time $\mathrm{t}_{\mathrm{QBS}}$. An expression for calculating $\mathrm{R}_{\mathrm{ex}}$ is given as follows:

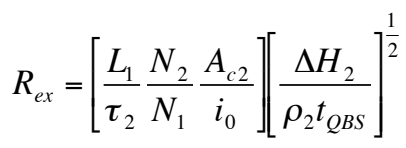

where $L_{1}$ is the inductance of the coil; $\mathrm{N}_{1}$ is the number of turns in the coil; and $\mathrm{N}_{2}$ is the number of turns in the secondary circuit. (For the magnet mandrel $N_{2}=1$.) $A_{c 2}$ is the cross-section area of the secondary circuit, and $\mathrm{i}_{0}$ is the starting current in the coil. $\square \mathrm{H}_{2}$ is the change in enthalpy of the material in the secondary circuit needed to induce quench back. (For the aluminum in the mandrel between $4 \mathrm{~K}$ and say $10 \mathrm{~K}, \square \mathrm{H}_{2}=11700 \mathrm{~J} \mathrm{~m}^{-3}$.) $\square_{2}$ is the electrical resistivity of the mandrel metal $\left(\square_{2}=1.42 \times 10^{-8} \square \mathrm{m}\right) . \square_{2}$ can be calculated using the following expression;

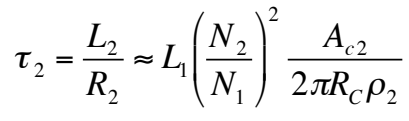

where $R_{C}$ is the average radius of the coil.

From equation 30 one can get an approximate value for $\mathrm{R}_{\mathrm{ex}}$, which is given using the following approximate expression; 


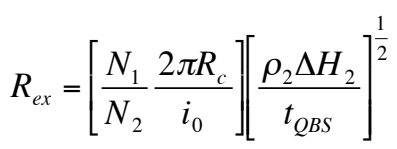

Table 4 shows the parameters needed to calculate the amount of coil resistance needed to cause quench back in a single focusing coil and the coupling coil. This resistance is compared with the resistance needed to protect a single magnet.

Table 4. Parameters of a Single Focusing and Coupling Magnet, Quench Back Resistance, Maximum Quench Back Voltage, Safe Discharge Resistance and The Maximum Safe Discharge Voltage

\begin{tabular}{|c|c|c|}
\hline Quench Parameter & Focusing & Coupling \\
\hline Number of Turns in a Single Magnet $\mathrm{N}_{1}{ }^{*}$ & 19304 & 15704 \\
\hline Coil Average Radius $\mathrm{R}_{\mathrm{C}}(\mathrm{m})$ & 0.305 & 0.783 \\
\hline Peak Magnet Current $\mathrm{i}_{0}(\mathrm{~m})$ & 250.7 & 213.2 \\
\hline Desired Quench Back Time $t_{\mathrm{QBS}}(\mathrm{s})$ & 1.32 & 2.65 \\
\hline Quench Back Resistance $\mathrm{R}_{\mathrm{ex}}(\mathrm{ohm})$ & 1.83 & 2.99 \\
\hline Maximum Quench Back Voltage (V) & 458 & 589 \\
\hline Safe Discharge Resistance $\mathrm{R}_{\mathrm{o}}(\mathrm{ohm})$ & 13.5 & 55.8 \\
\hline Maximum Safe Discharge Voltage (V) & 3374 & 11897 \\
\hline
\end{tabular}

The equation used to generate $\mathrm{R}_{\mathrm{ex}}$ assumes perfect coupling between the coil and the mandrel. For less than perfect coupling, one may take this into account by multiplying the resistance generated by equation 31 by a term such as $(1 / \square)^{0.5}$. This term increases the resistance for the focusing coil $(\square=0.82)$ by about ten percent. This term increases the resistance for the coupling coil $(\square=0.92)$ by about four percent.

From Table 4, it is clear that the resistance needed to induce quench back is much less than the resistance needed to protect the magnet. Quench back causes the whole coil to turn normal early and in doing so reduces the voltages that are in the coil circuits. If one wants to induce quench back in three focusing magnets in series, on must increase the quench back resistance $R_{\text {ex }}$ by a factor of three. The voltage on the circuit leads needed to induce quench back is also increased a factor of three. If one wants to induce quench back in two coupling magnets in series, on must increase the quench back resistance $\mathrm{R}_{\mathrm{ex}}$ by a factor of two. The voltage on the circuit leads needed to induce quench back is also increased a factor of two. In both cases, the voltages needed when all the focusing magnets and coupling magnets are in series are quite reasonable.

It is important to determine whether the magnets going normal on their own will induce quench back, thus speeding up the process of turning the whole magnet normal. It is clear that an external resistor will speed up the quench process within both the focusing magnet (2.27 seconds versus 3.21 seconds) and the coupling magnet (4.11 seconds versus 5.57 seconds). If the time to quench back is sufficiently short, the magnets will become entirely normal faster, thus reducing the quench hot spot temperature and the voltages in the magnet during the quench. 
In the focusing magnet, the quench within the magnet propagates in three dimensions in time when $0<\mathrm{t}<0.19 \mathrm{~s}$. The focusing magnet quench is two dimensional when $0.19<\mathrm{t}<1.14 \mathrm{~s}$. The focusing quench is one dimensional for $\mathrm{t}>1.14 \mathrm{~s}$. In the coupling magnet, the quench propagates in three dimensions in time when $0<\mathrm{t}<0.61 \mathrm{~s}$. The coupling magnet quench is two dimensional when $0.61<\mathrm{t}<2.04 \mathrm{~s}$. The coupling quench is one dimensional for $\mathrm{t}>2.04 \mathrm{~s}$.

Since the desired quench back time is a little greater than the time where the quench becomes one dimensional (1.32 s for the focusing magnet and $2.65 \mathrm{~s}$ for the coupling magnet), one should use the two dimensional scenario for the quench process leading up to quench back within the magnet. If the calculated quench back time based on two dimensional quench propagation is less than the time where the quench process becomes one dimensional, there will be a speed up of the time the coil becomes fully normal. As a result, both the hot spot temperature and the in coil voltages will be reduced compared to the cases where there is no quench back from the mandrel to the coil.

The time to the start of quench back $\mathrm{t}_{\mathrm{QB}}$ can be estimated for a two dimensional quench if the $\mathrm{R}$ direction and the $\mathrm{Z}$ direction using the following approximate expression;

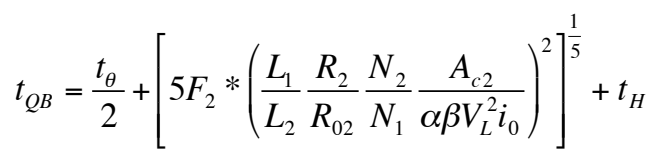

where $t_{\square}$ is the time to propagate the quench around the coil; $L_{1}$ is the self-inductance of the magnet coil system with $\mathrm{N}_{1}$ turns; and $\mathrm{L}_{2}$ is the self-inductance of the secondary circuit with $\mathrm{N}_{2}$ turns ( $\mathrm{N}_{2}=1$ for the MICE magnets). $\mathrm{R}_{2}$ is the resistance of the secondary circuit; $A_{c 2}$ is the cross-section area of the secondary winding (the mandrel); $V_{L}$ is the quench propagation velocity along the wire (defined by Equation 11) and $\mathrm{i}_{0}$ is the starting current in the coil (at $\mathrm{t}=0$ ). $\square$ and $\square$ are quench propagation velocity ratios in the $\mathrm{R}$ and $\mathrm{Z}$ directions respectively that are defined Equations $13 \mathrm{a}$ and $13 \mathrm{~b} . \mathrm{t}_{\mathrm{H}}$ is the time constant for the heat to jump from the mandrel across a $1 \mathrm{~mm}$ thick plane of ground insulation. (For the MICE magnets $t_{\mathrm{H}}<0.01$ seconds, so it can be neglected.)

The two-dimensional resistance growth term $\mathrm{R}_{02}$ is defined as follows;

$$
R_{02}=\frac{2 \square R_{c} N_{1} \square_{1}}{T_{c} L_{c} A_{c 1}} \frac{r+1}{r}
$$

where $\square_{1}$ is the resistivity of the superconductor matrix material $\left(\square_{1}=1.55 \times 10^{-10} \square \mathrm{m}\right.$ in our case); $a_{1}$ is the average radius of the coil; $A_{c 1}$ is the cross-section area of the conductor $\left(\mathrm{A}_{\mathrm{cl}}=1.38 \times 10^{-6} \mathrm{~m}^{2}\right.$ in our case $) ; \mathrm{N}_{1}$ is the number of turns in the coil; and $\mathrm{r}$ is the copper to superconductor ratio in the coil conductor $(r=4$ in our case).

The integral $\mathrm{j}^{2} \mathrm{dt}$ term for the secondary circuit $\mathrm{F}_{2}{ }^{*}$ can be estimated using the following expression for the secondary material at low temperature;

$$
F_{2}^{*}=F_{2}\left(T_{Q B}\right) \square F_{2}(4.2)=\square \complement^{o B} j_{2}(t)^{2} d t=\frac{\square H_{2}}{\square_{2}}
$$

where $\mathrm{T}_{\mathrm{QB}}$ is the secondary circuit temperature where quench back starts $\left(\mathrm{T}_{\mathrm{QB}}>7 \mathrm{~K}\right) ; \mathrm{t}_{\mathrm{QB}}$ is the time to the start of quench back; and $\mathrm{j}_{2}(\mathrm{t})$ is the current density in the secondary as a 
function of time. $\square \mathrm{H}_{2}$ is the enthalpy change per unit volume from $4.2 \mathrm{~K}$ to $\mathrm{T}_{\mathrm{QB}}$, and $\square_{2}$ is the resistivity of the secondary circuit material over the temperature range from $4.2 \mathrm{~K}$ to $\mathrm{T}_{\mathrm{QB}}$. (For our case with $\mathrm{T}_{\mathrm{QB}}=10 \mathrm{~K}, \square \mathrm{H}_{2}=11700 \mathrm{~J} \mathrm{~m}^{-3}$, and $\square_{2}=1.42 \times 10^{-8} \square \mathrm{m}$.)

One can simplify equation 32 so that $\mathrm{t}_{\mathrm{OB}}$ is only a function of the material properties, the coil dimensions; the quench propagation velocity along the wire $\mathrm{V}_{\mathrm{L}}$; the copper to superconductor ratio $r$ and the starting current density $j_{0}$ in the magnet conductor. In order to do this one must define $\mathrm{L}_{1}, \mathrm{~L}_{2}$ and $\mathrm{R}_{2}$ as follows;

$$
\begin{aligned}
& L_{1} \square \frac{\square_{0} \square a_{1}^{2} N_{1}^{2}}{\ell_{1}} g_{1}\left(a_{1}, \ell_{1}\right), \\
& L_{2} \square \frac{\square_{0} \square a_{2}^{2} N_{2}^{2}}{\ell_{2}} g_{2}\left(a_{2}, \ell_{2}\right),
\end{aligned}
$$

and

$$
R_{2}=\frac{2 \square a_{2} \square_{2 M} N_{2}}{A_{c 2}}
$$

where $\mathrm{a}_{1}$ is the average coil radius $\left(\mathrm{a}_{1}=\mathrm{R}_{\mathrm{c}}\right) ; \mathrm{a}_{2}$ is the average secondary circuit radius; $\ell_{1}$ is the coil average length $\left(\ell_{1}=\mathrm{L}_{\mathrm{c}}\right) ; \ell_{2}$ is the secondary circuit average lengths; $\mathrm{N}_{1}$ is the number of turns in the coil; and $\mathrm{N}_{2}$ is the number of turns in the secondary circuit. $\square_{0}$ is the magnetic permeability of vacuum $\left(\square_{0}=4 \square \times 10^{-7} \mathrm{Hm}^{-1}\right) . \quad \mathrm{g}_{1}$ is the geometric inductance term for the coil and $\mathrm{g}_{2}$ is the geometric inductance term for the secondary circuit. $A_{\mathrm{c} 2}$ is the cross-sectional area of the secondary circuit and $\square_{2 \mathrm{M}}$ is the electrical resistivity of the material in that circuit.

If the coils are well coupled, the average radii are nearly the same and the average lengths are nearly the same so the inductance geometric functions $g_{1}$ and $g_{2}$ are the same. Using the well-coupled coil approximation, one can simplify the expression for $\mathrm{t}_{\mathrm{QB}}$ given by equation 32 to the following approximate form;

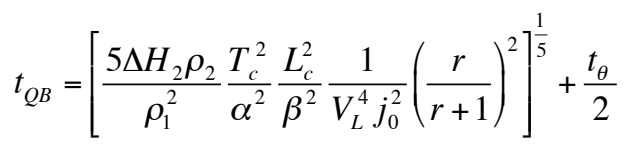

where $\square \mathrm{H}_{2}$ is the mandrel enthalpy change needed to induce quench back; $\square_{1}$ is the electrical resistivity of the matrix material in the conductor. $\square_{2}$ is the electrical resistivity of the mandrel material. ( $\square_{2}$ is constant over a wide temperature range.) $T_{c}$ is thickness of the coil; and $\mathrm{L}_{\mathrm{c}}$ is the length of the coil. $\square$ is defined by equation 13a, and $\square$ is defined by equation $13 \mathrm{~b}$. The quench velocity along the wire $\mathrm{V}_{\mathrm{L}}$ is defined by equation $11 . \mathrm{j}_{0}$ is the starting current density in the conductor cross-section; $r$ is the copper to superconductor ratio for the conductor. $t_{\square}$ is the time for the quench to propagate the third dimension (half way around the coil).

To be conservative one should use the minimum value of $\square_{1}$ (at say $10 \mathrm{~K}$ ). It is more realistic to use a larger value of $\square_{1}$ that represents the average resistivity of the matrix as the quench develops in the coil. This value may be 3 to 5 times the minimum value of $\square_{1}$. Increasing $\square_{1}$ by a factor of 3 will reduce $t_{\mathrm{QB}}-\mathrm{t}_{\sqrt{\mathrm{V}}} / 2$ by about 36 percent. 
Table 5. Quench Back Parameters of a Single Focusing and Coupling Magnet, Time for Quench Back when $\square_{1}=1.55 \times 10^{-10} \square \mathrm{m}$, and Time for Quench Back when $\square_{1}=4.65 \times 10^{-10} \square \mathrm{m}$

\begin{tabular}{|c|c|c|}
\hline Quench Parameter & Focusing & Coupling \\
\hline Coil Length in $\mathrm{Z}$ Direction $\mathrm{L}_{\mathrm{C}}(\mathrm{m})$ & 0.210 & 0.250 \\
\hline Coil Thickness in R Direction $\mathrm{T}_{\mathrm{C}}(\mathrm{m})$ & 0.084 & 0.116 \\
\hline Coil Average Radius $\mathrm{R}_{\mathrm{C}}(\mathrm{m})$ & 0.305 & 0.783 \\
\hline Peak Magnet Current $\mathrm{i}_{0}(\mathrm{~m})$ & 250.7 & 213.2 \\
\hline Conductor Peak Current Density $\mathrm{j}_{0}\left(\mathrm{~A} \mathrm{~m}^{-2}\right)$ & $1.81 \times 10^{8}$ & $1.54 \times 10^{8}$ \\
\hline Quench Propagation Velocity $\left(\mathrm{m} \mathrm{s}^{-1}\right)$ & 5.2 & 4.0 \\
\hline Quench Back Time $\square_{1}=1.55 \times 10^{-10} \square \mathrm{m}(\mathrm{s})$ & 1.07 & 2.17 \\
\hline Quench Back Time $\square_{1}=4.65 \times 10^{-10} \square \mathrm{m}(\mathrm{s})$ & 0.72 & 1.51 \\
\hline
\end{tabular}

* Note; in both magnets the mandrel is a single turn secondary $\left(\mathrm{N}_{2}=1\right)$, and $\square_{2}=1.42 \times 10^{-8} \square \mathrm{m}$.

Table 5 shows the quench back time for the focusing a coupling coil. When one uses the minimum value of $\square_{1}$, the quench back time is about the same as the time for the coil to completely quench. If one uses a value of $\square_{1}$ that is three times the minimum value, the quench back time is short enough that quench back makes a difference in terms of the hot spot temperature and the voltages within the coil. In general, one might conclude that quench back has only a moderate effect on the quenching of a single coil.

The quench back time doesn't increase when magnets are in series. If three focusing magnets are in series the quench back time is $0.72 \mathrm{~s}\left(\square_{1}=4.65 \times 10^{-10} \square \mathrm{m}\right)$. If two coupling magnets are in series, the quench back time is $1.51 \mathrm{~s}\left(\square_{1}=4.65 \times 10^{-10} \square \mathrm{m}\right)$. The quench back time applies to all of the coils in the string including those coils that did not originally turn normal.

Once a focusing coil starts to quench back, the coil becomes fully normal in $0.95 \mathrm{~s}$. (The $0.95 \mathrm{~s}$ is the time that the quench propagates from the focusing coil end flanges to the center of the coil.) When the second coupling coil starts to quench by quench-back, it becomes fully normal in about $1.46 \mathrm{~s}$. (The $1.46 \mathrm{~s}$ is the time that the quench propagates from the coupling coil end flanges to the center of the magnet.)

Quench back from the magnet mandrel permits one to hook the three coupling magnets in series. Quench back also permits the two coupling magnets to be hooked in series. The use of a mandrel in these magnets is not so desirable from a stress standpoint, because there are large cool down stresses in the aluminum mandrel [13]. A mandrel fabricated from copper or bronze would not exhibit large stresses due to the difference in contraction coefficient between the conductor and the mandrel material. The mandrel is desirable form the standpoint of quenching and it is also very useful for ensuring that the magnet operates at a uniform temperature [14].

Since the Italian design detector magnet does not have a mandrel to quench back from, one may not be able to put like coils in series between the two magnets. Of particular concern is the long center coil that is in series with the two end coils. The Italian detector magnets can have quench back provided a shorted secondary winding is wound on the outside of the detector magnet coils. A full layer of ground plane insulation is needed between the shorted secondary winding and the coils. 


\section{Passive Quenches in the Focusing and Coupling Magnets}

Between relatively rapid propagation of the quench in the coils (see Table 3 ) and quench back induced in the non-quenching coils (see Table 5), it is clear that the focusing coils and the coupling coils will quench passively, without removing any energy from the coils. Because the coils quench rapidly, the integral of $\mathrm{j}^{2} \mathrm{dt}$ is low enough so that the hot spot temperature at the spot where the quench started is less than $300 \mathrm{~K}$. If the coils are allowed to quench without any external quench protection, all of the magnet storedenergy is shared by all of the coils in the string that are involved in the quench process.

The quench process can be modeled by dividing the quench time into time steps $\square \mathrm{t}_{1}$ through $\square \mathrm{t}_{\mathrm{N}}$. The sum of the time steps $\square \mathrm{t}_{1}$ through $\square \mathrm{t}_{\mathrm{N}}$ is some time like 10 to $15 \mathrm{~s}$ (to a point where the remaining stored magnetic energy is small). At the very minimum, the first three time steps should be dictated by the quench process within the magnet (or magnets). From then on, the remaining time steps can be the same. I suggest the following $\square \mathrm{t}_{1}=\mathrm{t}_{\square}, \square \mathrm{t}_{2}=\mathrm{t}_{\mathrm{QB}}-\mathrm{t}_{\square}$, and $\square \mathrm{t}_{3}=\mathrm{t}_{\mathrm{Z}} / 2$. From then on the time steps can be in onesecond intervals. If one wants to look at how the quench progresses within the coil, one can further subdivide steps $\square \mathrm{t}_{1}, \square \mathrm{t}_{2}$, and $\square \mathrm{t}_{3}$. (A program called QUENCH, written in the late 1960s and modified in the mid 1970s subdivides the early time steps to allow on to look at the quench within the coil. QUENCH does a reasonably good job of modeling quench behavior in magnets despite the fact that the model for quench propagation velocities within the coil is often incorrect.)

Since the quench progression within the coil is modeled using three time steps, the regions of the coil that are quenching during those time steps should be worked with separately. For example, a magnet that is in series with the coil quenching does not start to quench until time step 3 when the quench is induced within that magnet through quench back. For the first three time steps the following resistances can be calculated;

$$
\begin{array}{llll}
\text { For } \mathrm{t}=0 & \ell_{0}=0, \text { and } & R_{0}=0 . & -36 \mathrm{a}- \\
\text { For } \mathrm{t}=\mathrm{t}_{1} & \ell_{1}=\frac{\square^{3} R_{c}^{3} \square \square}{a b}, \text { and } & R_{1}=\frac{\square_{1} \ell_{1}}{A_{c 1}} \frac{r+1}{r}, \text { where } \square_{1}=1.55 \times 10^{-10} \square \mathrm{m} . & -36 \mathrm{~b}- \\
\text { For } \mathrm{t}=\mathrm{t}_{2} & \ell_{2}=\square R_{c} \frac{V_{L}^{2} t_{2}^{2} \square \square}{a b} .
\end{array} \quad \begin{array}{ll}
R_{2}=\frac{\square_{2} \ell_{2}}{A_{c 1}} \frac{r+1}{r}, \text { where } \square_{2}=4.65 \times 10^{-10} \square \mathrm{m} . & -36 \mathrm{c}-
\end{array}
$$

When the quench starts near the end of the coil, divide $\ell_{1}$ and $\ell_{2}$ by two.

$$
\begin{array}{lll}
\text { For } \mathrm{t}=\mathrm{t}_{3} \quad \ell_{3}=\square R_{c} N_{T}, \text { and } \quad R_{3}=\frac{\square \square_{3}\left(T_{c 1}\right) \ell_{3}}{A_{c 1}}+\left(N_{c o i l} \square 1\right) \frac{\square_{3}\left(T_{c o}\right) \ell_{3}}{A_{c 1}} \sqrt{\frac{r+1}{r}} . & -36 \mathrm{~d}- \\
\text { For } \mathrm{t}=\mathrm{t}_{\mathrm{n}} \quad \ell_{n}=2 \ell_{3} \text { for } \mathrm{n}>3 \text {, and } R_{n}=\frac{\square \square_{n}\left(T_{c 1}\right) \ell_{3}}{A_{c 1}}+\left(N_{c o i l} \square 1\right) \frac{\square_{n}\left(T_{c o}\right) \ell_{3}}{A_{c 1}} \sqrt{r} . & -36 \mathrm{e}-
\end{array}
$$

For the equations above $\ell_{0}$ through $\ell_{n}$ are the lengths of conductor in the normal state as a function of time. $R_{c}$ is the average radius of the coil, and $\mathrm{N}_{T}$ is the number of turns in the coil. $\square$ is the velocity ratio in the $\mathrm{r}$ direction; $\mathrm{a}$ is the conductor plus insulation thickness in the $\mathrm{r}$ direction; $\square$ is the velocity ratio in the $\mathrm{z}$ direction; and $\mathrm{b}$ is the conductor plus insulation dimension in the $\mathrm{z}$ direction. $\mathrm{A}_{\mathrm{c} 1}$ is the conductor cross-section area. (In MICE focusing and coupling coils $A_{c 1}=1.38 \times 10^{-6} \mathrm{~m}^{2}$.) $\mathrm{N}_{\text {coil }}$ is the number of coils in the magnet string. (For the focusing magnet, $\mathrm{N}_{\text {coil }}=6$; for the coupling magnet $\mathrm{N}_{\text {coil }}=2$.) For the simple model, and for times $t_{3}$ through $t_{N}$, the value of $\square$ is determined by the average temperature of the coil in question. The coil where the quench starts is always hotter. 
The next set of equations are used to calculate the energy in the magnet system $\mathrm{E}$, which has an overall self-inductance $\mathrm{L}_{\mathrm{MS}}$. If one knows energy the energy in the magnet at the end of the time step, one can calculate the magnet system current $i_{c}$ at the end of the time step. It is assumed that none of the magnet stored energy ends up in the mandrel or in external resistors. Given what we know from the Fermilab MUCOOL solenoid, twenty to thirty percent of the magnet stored energy ends up in the mandrel, so the quench analysis presented here is conservative.

$$
\text { For } \mathrm{t}=0, E_{0}=\frac{L_{M S}}{2} i_{0 c}^{2} \text {. }
$$

$\mathrm{L}_{\mathrm{MS}}$ is the inductance of the magnet system, and $\mathrm{i}_{0}$ is the starting current for the system. For a single focusing magnet in the flip mode, $\mathrm{L}_{\mathrm{MS}}=98.6 \mathrm{H}$. For three focusing magnets in the flip mode in series, $\mathrm{L}_{\mathrm{MS}}=295.8 \mathrm{H}$. For a single focusing magnet in the non-flip mode, $\mathrm{L}_{\mathrm{MS}}=138.2 \mathrm{H}$. For three focusing magnets in the non-flip mode hooked in series, $\mathrm{L}_{\mathrm{MS}}=414.6 \mathrm{H}$. For a single coupling magnet, $\mathrm{L}_{\mathrm{LM}}=563 \mathrm{H}$. For a pair of coupling magnets in series, $\mathrm{L}_{\mathrm{LM}}=1126 \mathrm{H}$.

One can calculate the energy change in magnet circuit as the magnet quenches using the equations given below. The equations below assume that the mandrel absorbs very little of the energy in the magnet, because $\square_{\mathrm{b}}<<\left(\square_{\mathrm{l}}+\square_{\mathrm{b}}\right)$. The energy change per unit $\square \mathrm{t}$ that leads to a current change in coil can be calculated as follows;

$$
\begin{aligned}
& \text { For } \mathrm{t}=\mathrm{t}_{1}, E_{1}=E_{0} \square \square E_{1} \text {, where } \square E_{1}=i_{0 c}^{2} \frac{R_{1}}{2} \square \mathrm{t}_{1} \text {. Therefore, } i_{1 c}=\stackrel{\square}{\square L_{M S}} \frac{L^{0.5}}{\square} . \quad-37 \mathrm{~b}- \\
& \text { For } \mathrm{t}=\mathrm{t}_{2}, E_{2}=E_{1} \square \square E_{2} \text {, where } \square E_{2}=i_{1 c}^{2} \frac{R_{1}+R_{2}}{2} \square \mathrm{t}_{2} \text {. Therefore, } i_{2 c}=\frac{\square}{\square} \frac{E_{2} L_{M S}}{\square} \stackrel{0.5}{\square} \cdot \quad-37 \mathrm{c}- \\
& \text { For } \mathrm{t}=\mathrm{t}_{3}, E_{3}=E_{2} \square \square E_{3} \text {, where } \square E_{3}=i_{2 c}^{2} R_{2} \square \mathrm{t}_{3} \text {. Therefore, } i_{3 c}=\sqrt[\square]{L_{M S}} \frac{P_{3}^{.5}}{\square} . \quad-37 \mathrm{~d}- \\
& \text { For } \mathrm{t}=\mathrm{t}_{\mathrm{n}}, E_{n}=E_{n \square 1} \square \square E_{n} \text {, where } \square E_{n}=i_{(n \square 1) c}^{2} R_{n \square !} \square \mathrm{t}_{\mathrm{n}} \text {. Therefore, } i_{n c}=\stackrel{\square}{\square} \frac{\square E_{n}}{L_{M S}} \stackrel{0.5}{\square} \cdot-37 \mathrm{e}-
\end{aligned}
$$

In the equations above, $\square \mathrm{E}_{\mathrm{n}}$ is the magnet energy change during a time step $\square \mathrm{t}_{\mathrm{n}} ; \mathrm{R}_{\mathrm{n}-1}$ is the magnet system resistance at the start of the time step $\square t_{n}$; and $R_{n}$ is the magnet system resistance at the end of the time step $\square t_{n}$. One must determine the resistance $R_{n}$, which is a function of the average coil temperature $T_{n}$, which in turn is a function of the average thermal energy per unit volume stored in the coil ( $\mathrm{E}_{\mathrm{n}} /$ coil volume).

Equations $37 \mathrm{~b}$ through $37 \mathrm{e}$ assume that the mandrel plays no role in the quench process except to cause quench back. In fact, in the MICE magnets, the mandrel can absorb up thirty percent of the magnet stored-energy at the end of the quench. The reason that the mandrel is significant is that it is fabricated from a conductive material. The mandrel time constant $\square$, changes very little during the quench process, because the mandrel material resistivity does not change with temperature, when the temperature is less than $120 \mathrm{~K}$. At the end of the quench, $\square_{2}$ can be of the same order as $\square_{1}$, so a significant portion of the quench energy can end up in the mandrel.

At any time during the quench process the current in the coil and the mandrel can have the following values; 


$$
\begin{array}{ll}
i_{n C}=\frac{\square_{1 n}}{\square_{1 n}+\square_{2}} i_{n}, \text { where } \square_{1 n}=\frac{L_{M S}}{R_{n}} \text { and } \square_{2} \square \frac{L_{M S}}{N_{c o i l} R_{M}} \frac{\square_{N}}{N_{1}} \square^{2} \text {, and } & -38 \mathrm{a}- \\
i_{n M}=\frac{\square_{2}}{\square_{1 n}+\square_{2}} i_{n} \frac{\square_{1}}{N_{1}} \cdot \mathrm{R}_{2 \mathrm{M}} \text { is the secondary circuit resistance, where; } & -38 \mathrm{~b}- \\
R_{2 M}=\frac{2 \square R_{c} \square_{2 M} N_{2}}{A_{c 2}} & -38 \mathrm{c}-
\end{array}
$$

The magnet mandrel has is a single turn secondary so $\mathrm{N}_{2}=1$.

When, L is large enough to cause a diversion of the magnet current into the mandrel, the energy in the magnet circuit $E_{n}$ and the coil current $i_{n c}$ can be calculated using the following expressions for various values of $t$;

For $\mathrm{t}=0, E_{0}=\frac{L_{M S}}{2} i_{0 c}^{2}$. $-39 c-$

For $\mathrm{t}=\mathrm{t}_{1}, E_{1}=E_{0} \square\left(P_{C 1} \square P_{M 1}\right) \square t_{1} ; P_{C 1}=i_{0 c}^{2} \frac{R_{1 c}}{2} ; P_{M 1}=0 ;$ and $i_{1 c}=\frac{\square_{11}}{\square_{11}+\square_{2}} \frac{\square}{L_{M S}} \frac{E_{1}}{L^{0.5}}$ $-39 b-$

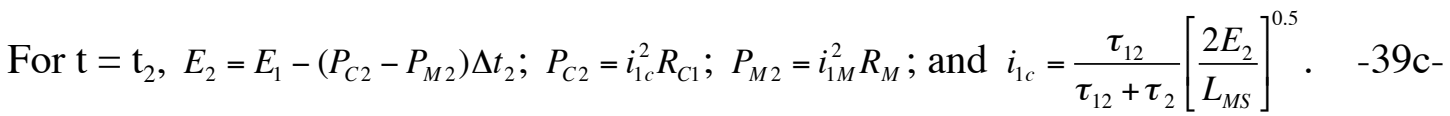

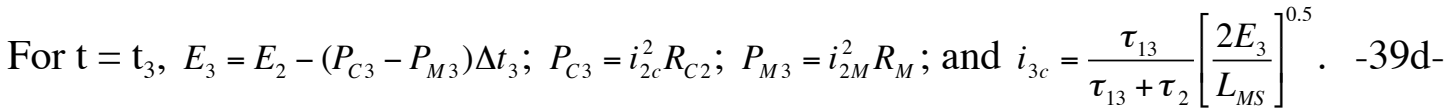

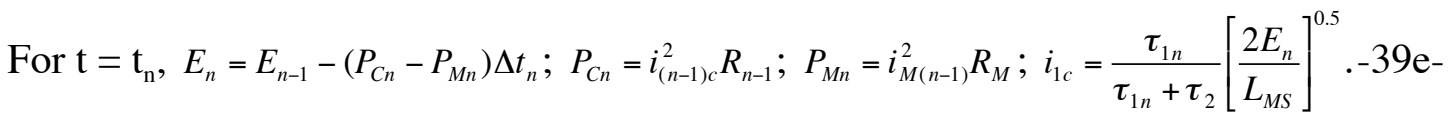

The final equations determine $\mathrm{F}^{*}\left(\mathrm{~T}_{\mathrm{M}}\right)$. From $\mathrm{F}^{*}\left(\mathrm{~T}_{\mathrm{M}}\right)$, the hot spot temperature at the point where the quench starts $\mathrm{T}_{\mathrm{M}}$ can be determined;

$$
\begin{array}{lll}
\text { For } \mathrm{t}=0, & F_{0} *\left(T_{M}\right)=0 . \mathrm{T}_{\mathrm{M}}=4.2 \mathrm{~K} & -40 \mathrm{a}- \\
\text { For } \mathrm{t}=\mathrm{t}_{1}, & F_{1} *\left(T_{M}\right)=F_{0} *\left(T_{M}\right)+\frac{i_{0 C}^{2}}{A_{c}^{2}} \square t_{1} . \mathrm{T}_{\mathrm{M}} \text { can be found in figure 3. } & -40 \mathrm{~b}- \\
\text { For } \mathrm{t}=\mathrm{t}_{2}, & F_{2} *\left(T_{M}\right)=F_{1} *\left(T_{M}\right)+\frac{i_{1 C}^{2}}{A_{c}^{2}} \square t_{2} . \mathrm{T}_{\mathrm{M}} \text { can be found in figure 3. } & -40 \mathrm{c}- \\
\text { For } \mathrm{t}=\mathrm{t}_{3}, & F_{3} *\left(T_{M}\right)=F_{2} *\left(T_{M}\right)+\frac{i_{2 C}^{2}}{A_{c}^{2}} \square t_{2} . \mathrm{T}_{\mathrm{M}} \text { can be found in figure 3. } & -40 \mathrm{~d}- \\
\text { For } \mathrm{t}=\mathrm{t}_{\mathrm{n}}, & F_{n} *\left(T_{M}\right)=F_{n \square 1} *\left(T_{M}\right)+\frac{i_{(n \square 1)}^{2}}{A_{c}^{2}} \square t_{n} . \mathrm{T}_{\mathrm{M}} \text { can be found in figure 3. }
\end{array}
$$

$\mathrm{F}^{*}\left(\mathrm{~T}_{\mathrm{M}}\right)$ is the integral of $\mathrm{j}^{2} \mathrm{dt}$ defined by equation 16 where $\mathrm{i}_{\mathrm{n}-1}$ is the current at $\mathrm{t}=\mathrm{t}_{\mathrm{n}-1}$ and $\mathrm{i}_{\mathrm{n}}$ is the current at $\mathrm{t}=\mathrm{t}_{\mathrm{n}}$. $\mathrm{A}_{\mathrm{c}}$ is the cross-section area of the matrix. $A_{c}=\left(A_{c 1} r\right) /(r+1)$, where for both types of magnets $A_{c 1}=1.38 \times 10^{-8} \mathrm{~m}^{2}$ and $\mathrm{r}=4$.

Figure 6 compares a quench of a single focusing magnet with a quench of three focusing magnets in series. Figure 7 compares a quench of a single focusing magnet in the flip mode with a quench of a single focusing magnet in the non-flip mode. Both cases in Figure 7 have the same current $(250.7$ A). Figures 6 and 7 plot the current decay with time and the hot spot temperature with time. A comparison of Figures 6 and 7 shows that current flowing in the mandrel causes quench back, which reduces coil current more rapidly, because more of the coil resistance is involved in the quench. 


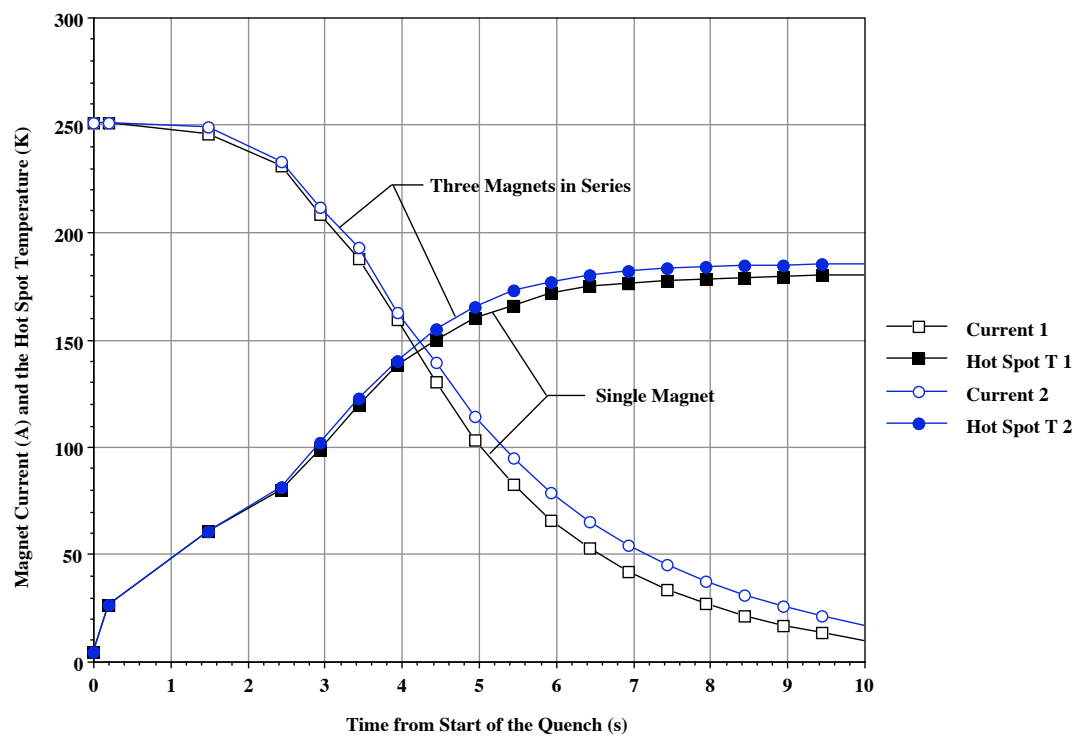

Figure 6. The Current Decay and Hot Spot Temperature of Single Focusing Magnet and Three Focusing magnets in Series in the Flip Mode as a Function of the Time since the Start of the Quench

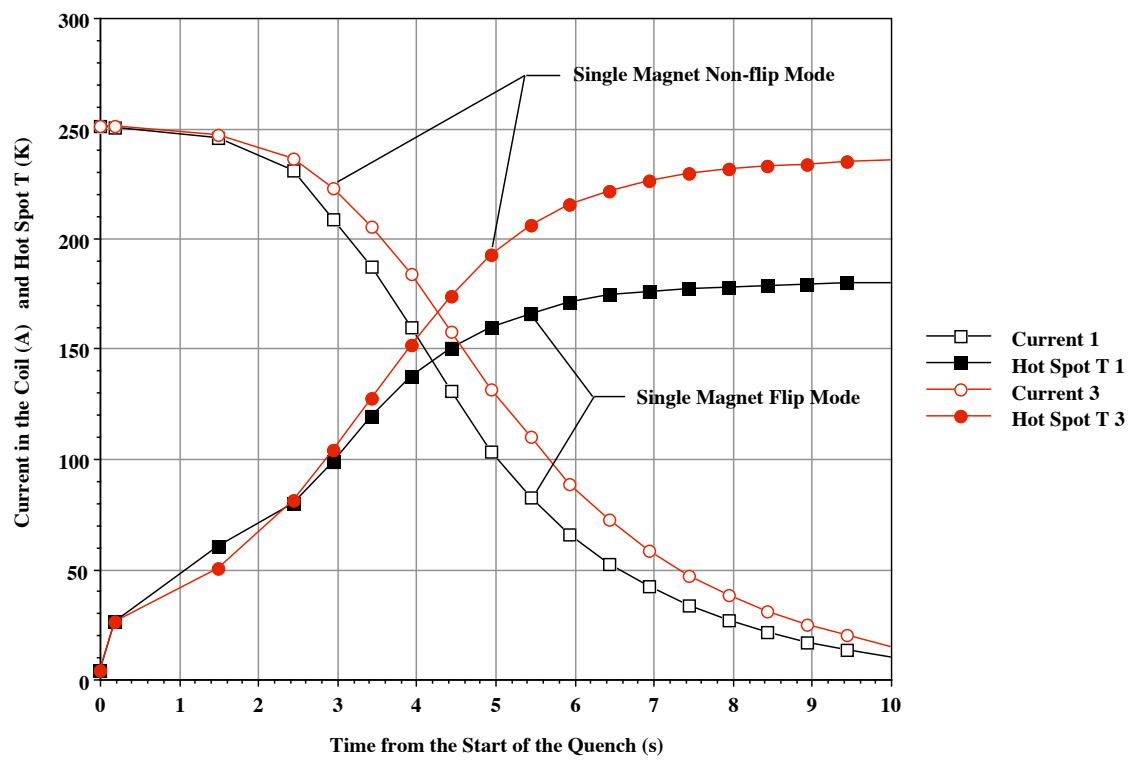

Figure 7. The Current Decay and Hot Spot Temperature of Single Focusing Magnet in the Flip Mode and the Non-flip Mode as a Function of the Time since the Start of the Quench

From Figure 6, one can see that the hot spot temperature difference due to three focusing magnets in series is less than $10 \mathrm{~K}$ higher than for a single focusing magnet. From Figure 7 one sees that operating a focusing magnet in the non-flip mode produces a $55 \mathrm{~K}$ higher hot spot temperature than in the flip mode. (The energy is 50 percent higher.)

Figure 8 compares a quench of a single coupling magnet with a quench of two coupling magnets in series at a current of 213.2 A. Figures 9 compares the current decay and the hot spot temperature with the time from the start of the quench for a coupling magnet with two different mandrel materials. A mandrel made from 6061 aluminum has a $\square_{1}=1.42 \times 10^{-8} \square \mathrm{m}$, and a half hard 1100 aluminum mandrel has $\square_{1}=2.84 \times 10^{-9} \square \mathrm{m}$. 


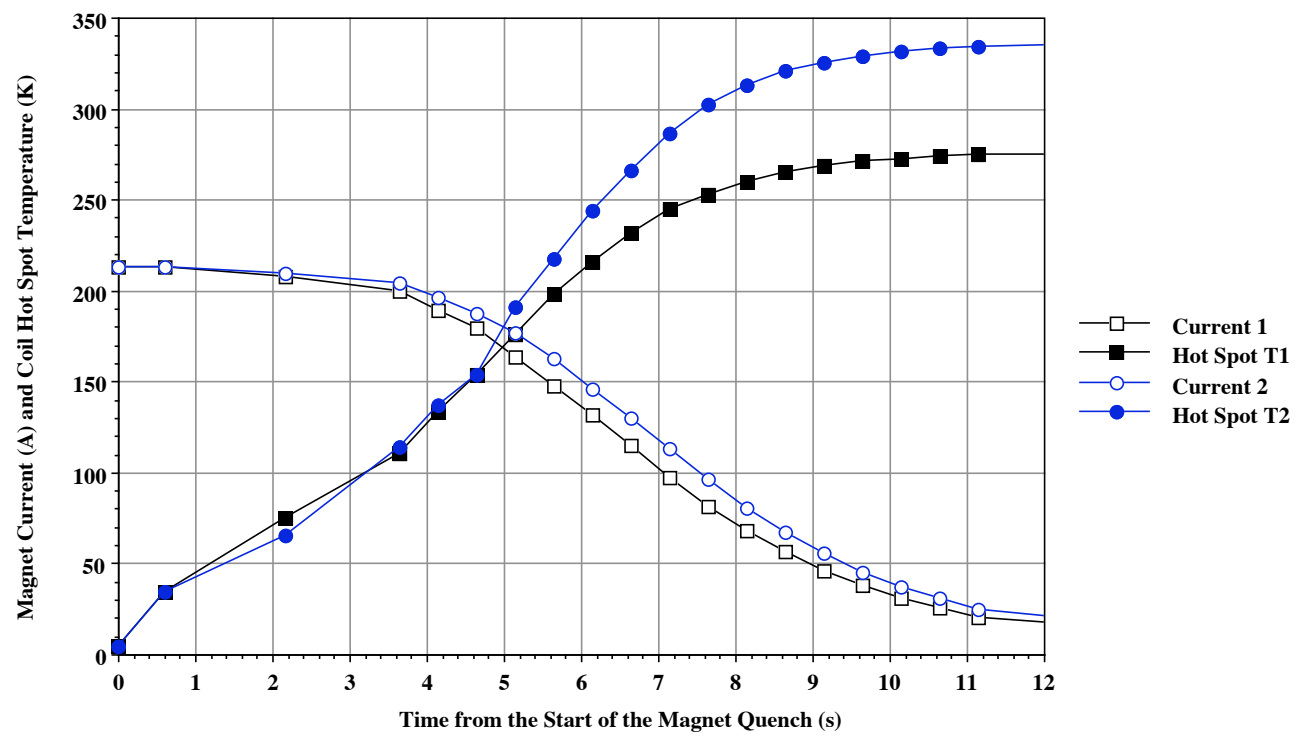

Figure 8. The Current Decay and Hot Spot Temperature of Single Coupling Magnet at Full Current and Two Coupling Magnets at Full Current as a Function of the Time since the Start of the Quench

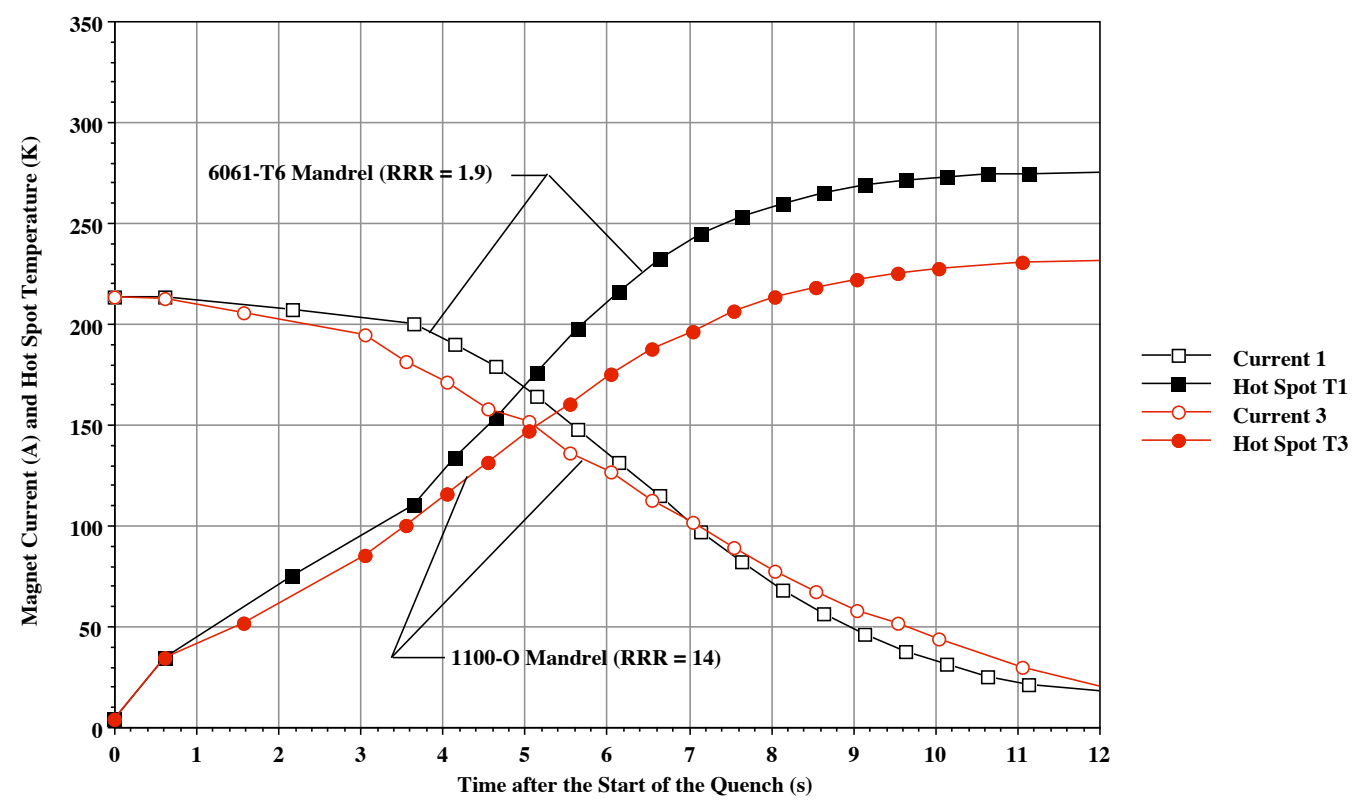

Figure 9. The Current Decay and Hot Spot Temperature of Single Coupling Magnet with a 6061-Al Mandrel and 1100-Al Mandrel as a Function of the Time since the Start of the Quench (Note: $\square_{1}=1.42 \times 10^{-8} \square \mathrm{m}$ for $6061 \mathrm{Al}$, and $\square_{1}=2.05 \times 10^{-9} \square \mathrm{m}$ for $1100-\mathrm{Al}$ at start of quench.)

From Figure 8 and Figure 9, it is clear that the quench of a single coupling magnet is safe from the standpoint of the hot-spot temperature. A hot-spot temperature of just over $280 \mathrm{~K}$ is a result of the high stored energy (12.8 MJ) for a single coupling magnet. Figure 8 shows that two coupling magnets in series (with a stored energy of 25.6 MJ) have a peak hot-spot temperature that is about $55 \mathrm{~K}$ higher that that of a single coupling magnet. From the standpoint of hot-spot temperature the quenches are safe, but they may not be safe from the standpoint of the voltage buildup in the coil. 
Figure 9 shows the effect of slowing the quench process down by using a more conductive mandrel. A half hard 1100 aluminum mandrel has an electrical resistivity that is a factor of seven lower than a 6061 aluminum mandrel at temperatures below $40 \mathrm{~K}$ [15]. Above $60 \mathrm{~K}$, the 1100-aluminum mandrel resistivity will be higher, but not as high as the 6061-aluminum mandrel resistivity. At temperatures below $40 \mathrm{~K}$, the mandrel current decay time constant will be about 2.8 seconds. The use of a low-resistivity mandrel appears to reduce the hot spot temperature by 35 to $40 \mathrm{~K}$. One reason for this is that much of the $\mathrm{F}^{*}$ gain occurs before the coil has gone completely normal due to quench back. The other reason is that the mandrel takes current away from the magnet coil.

The only problem that remains is the control of the voltages in the magnets. The voltage control system employed in the Lab G solenoid, which has peak stored-energies greater than 3.0 MJ [15], is shown in Figure 10. The voltage on the magnet leads is controlled using warm diodes and resistors. When the voltage across the individual coil leads exceeds $10 \mathrm{~V}$ (the maximum charging voltage for the entire magnet), current will start to flow through the diode stack. As the diode heat up the voltage drop goes down. The current is the coil is diverted through the resistor, reducing the hot spot temperature in the coil further. The diodes and resistors across the coils reduce the layer-to-layer voltages and the voltages to ground within the magnet coil.

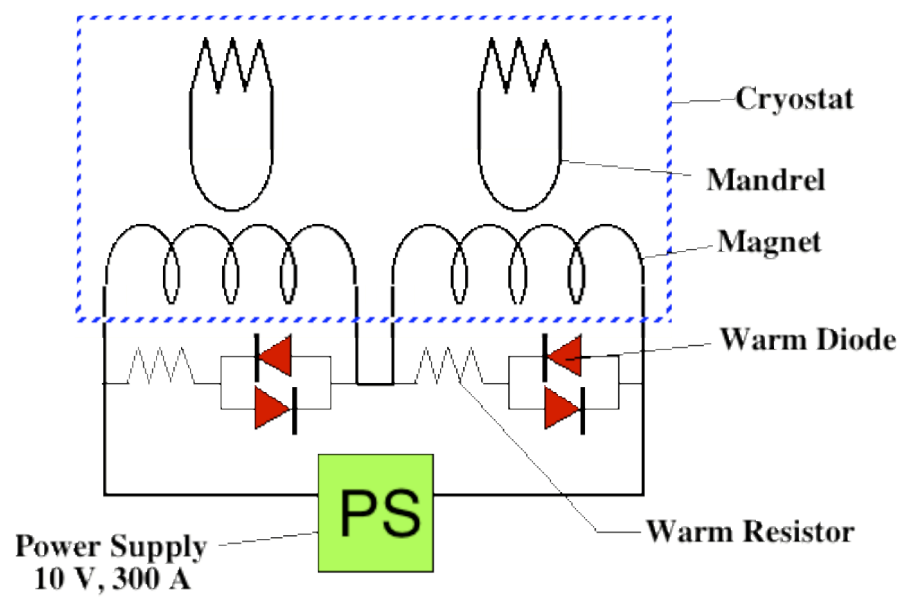

Figure 10. The Diode and Resistor Quench Protection System used in the Lab G Solenoid

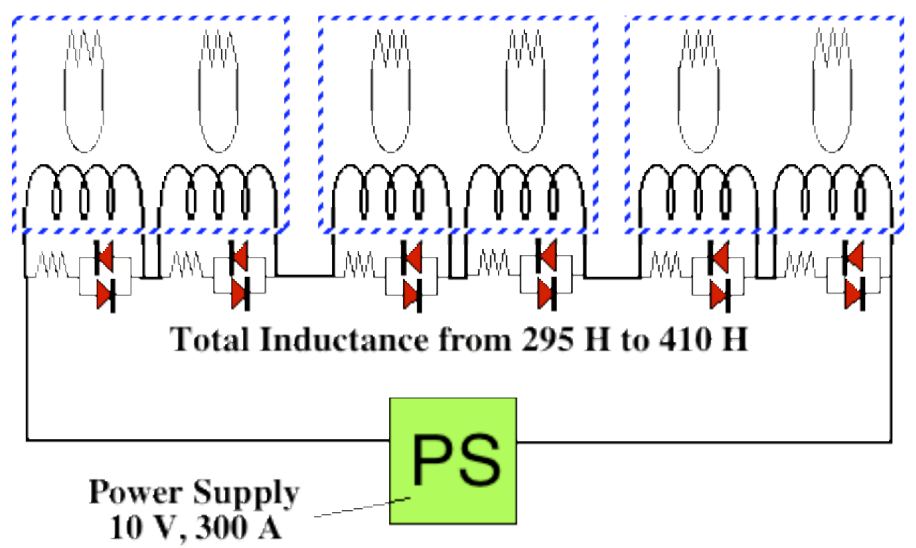

Figure 11. The Diode and Resistor Quench Protection System for Three Focusing Magnets in Series 
Figure 11 shows the quench protections system for three focusing magnets hooked up in series. The quench protection system shown in Figure 11 should have the same performance as the quench protection system shown in Figure 10. We know that the quench protections system shown in Figure 10 works very well, so the authors don't expect the three focusing magnets in series to behave much different from the Lab $G$ magnet. The previous statement is likely to be accurate up to a stored energy per magnet of about $3 \mathrm{MJ}$. The peak current in the focusing magnets for the low beta cases in the non-flip mode may result in magnet stored energies greater than 3.0 MJ. This may require that the non-flip low beta cases be operated at an average momentum of less than $200 \mathrm{MeV} / \mathrm{c}$, just as for many of the flip cases.

Figure 12 shows a method for controlling the voltages within a coupling magnet by using cold diodes and cold resistors. This method is commonly used to protect MRI magnets. The use of cold diodes and resistors has been demonstrated in a MRI magnet with a stored energy over 50 MJ. Figure 12 shows a diode resistor system that divides the coupling coil into two independent parts. This should reduce the peak voltages about a factor of four. Perhaps dividing the coupling coils into three parts or four parts is better from a voltage standpoint. Because the coupling magnet is cooled using a single small cooler, there are no leads to allow the diodes and resistors to run at room temperature. If one is willing to bring out pulsed leads, one can put the diodes and resistors outside of the magnet cryostat.

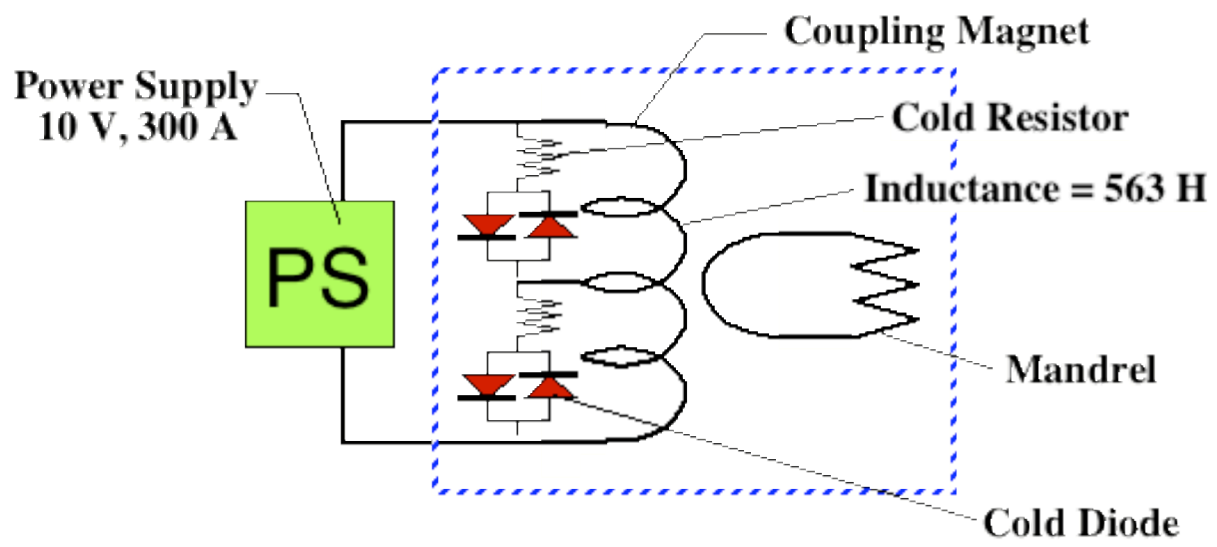

Figure 12. A Quench Protection System for a Single Coupling Magnet Based on the Use of Cold Diodes and Resistors inside of the Magnet Cryostat

Using cold diodes and resistors as a method of quench protection for the coupling magnet may allow one to reduce the quench back time for the coupling magnet. As the voltage in the diodes rises above $10 \mathrm{~V}$, current begins to flow in the resistor. If the resistor is non-inductive, one can maximize the rate of current rise in that resistor. One must design the resistor so that the integral of $j^{2} \mathrm{dt}$ is less than the burnout value.

The resistor that is across the inside turns of the magnet can be wound around the outside of the magnet coil. This resistor will heat the outside of the coil and cause that part of the coil to quench back early. As a result, the whole coupling magnet will become completely normal sooner. Speeding up the time for the whole magnet to become normal will reduce the hot-spot temperature in the magnet and the voltages within the magnet will also be reduced. 


\section{Magnetic Coupling between Various Magnets in MICE}

The power supply for the MICE magnets is determined by three factors. They are; 1) the required charge time for the magnet set, 2) the voltages generated by the charging of a nearby magnet, and 3) the total current change in a coil caused by the quenching of a nearby magnet or set of magnets. In addition, when a nearby superconducting magnet quenches, coupling from the quenching magnet to a second magnet mandrel may heat the second magnet mandrel enough to induce quench back in the second magnet. This coupling between a magnet and an adjacent magnet mandrel and quench back heating that results will be dealt with in a later section of this report.

The hook up of the magnets in the MICE cooling channel is quite clear. It has been proposed that the three focusing coils be hooked up in series so that they can be run from a single power supply. It has also been proposed that the two coupling coil can be hooked up in series and run from a single power supply. From the quench simulations it is clear that the coupling magnets can be hooked together in series. The question is whether the two coupling magnet should be hooked together in series. This section will look at the magnetic coupling for both alternatives.

The detector magnets have five coils. It is proposed that end coil 1 , the center coil, and end coil 2 be hooked up in series. End coils 1 and 2 will be tuned with respect to the center coil using a small power supply. The three-coil set is referred to as the spectrometer magnet. Each of the two match coils M1 and M2 is separately powered. It is proposed that M1 be in series with M1 in the detector magnet at the opposite end of the experiment; it is proposed that M2 be in series with M2 in the detector magnet at the opposite end of the experiment; and it is proposed that the two spectrometer-magnets be hooked up in series. The proposed detector magnet hookup is shown in Figure 13. This hookup is assumed for the magnet coupling discussions that follow.

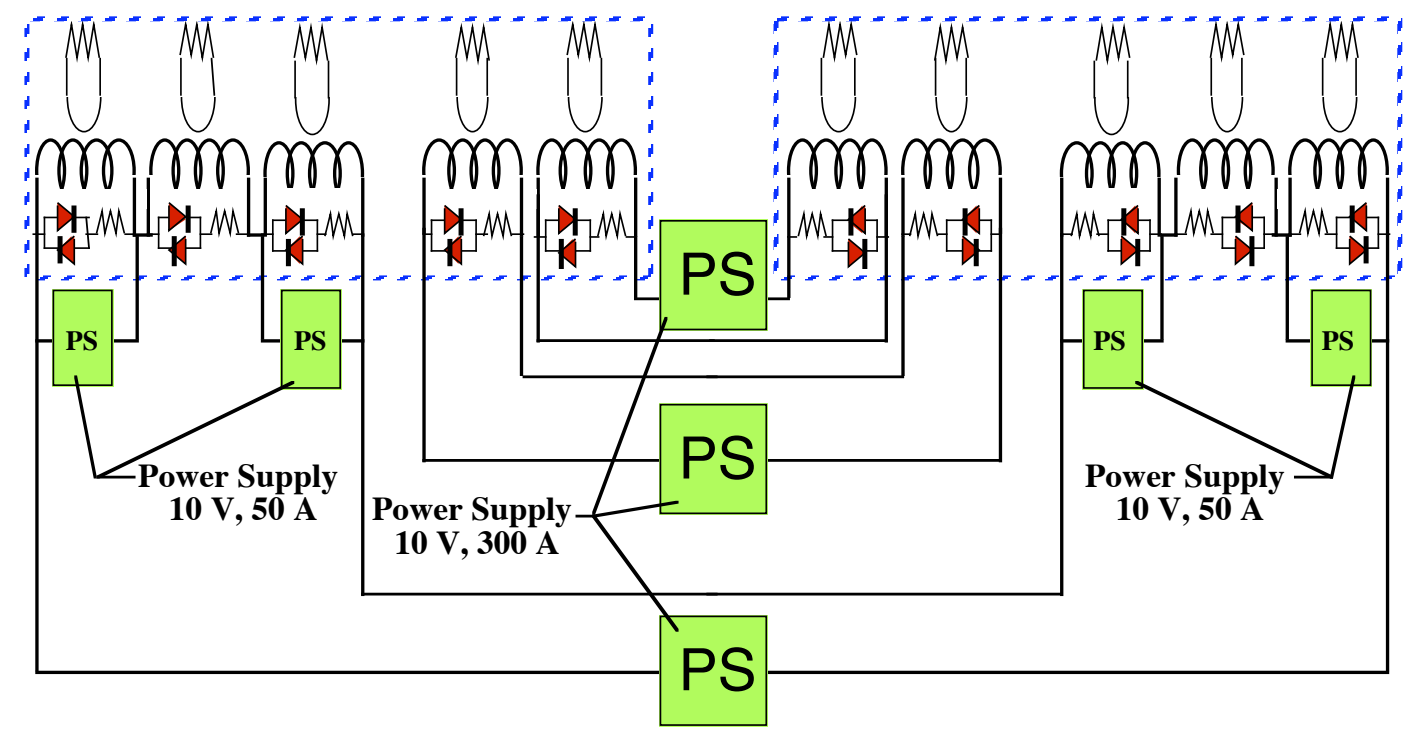

Figure 13. The Hookup for the Detector Magnet (The match coils from on detector magnet are hooked in series with the corresponding match coils of the other detector magnet. The spectrometer magnet coils of one detector magnet are hooked in series with the spectrometer coils of the other detector magnet. The small tuning power supplies on the end coils of spectrometer are separate for each magnet.) 


\section{a) Inductance calculations}

For calculating the inductance matrix, an analytic approach was chosen [17]; the results were verified using finite element software (FEA). The self-inductance of a loop of wire with the radius $R$ and circular cross section with radius $r_{a}$ is:

$$
L_{\text {self }}=\square_{0} R \text { 目 } \ln \frac{8 R}{r_{a}} \square \frac{7}{4} \text { 目 }
$$

For wires with a rectangular cross-section of height $\mathrm{h}$ and width $\mathrm{w}$, the following approximation gives good results:

$$
r_{a}=\sqrt{\frac{w \cdot h}{\square}}
$$

The mutual inductance between two current loops of radius $R_{1}$ and $R_{2}$ is calculated using;

$$
\left.L_{a b}=\square_{0} \sqrt{R_{1} R_{2}} \because \frac{2}{k} \square k\right) K(k) \square \frac{2}{k} E(k) \text { 昌 }
$$

where $\mathrm{E}(\mathrm{k})$ and $\mathrm{K}(\mathrm{k})$ are elliptic integrals, defined as

$$
\begin{aligned}
& E(k)=\square_{0}^{\prime 2} \sqrt{1 \square k^{2} \sin ^{2} \square} d \square \\
& K(k)=\square_{0}^{\prime 2} \frac{d \square}{\sqrt{1 \square k^{2} \sin ^{2} \square}}
\end{aligned}
$$

where $\mathrm{k}$ is a geometry factor, defined by the radii of the current loops $\mathrm{R}$ and the distance $\mathrm{z}$ between them:

$$
k=\sqrt{\frac{4 \mathrm{R}_{1} \mathrm{R}_{2}}{\left(\mathrm{R}_{1}+\mathrm{R}_{2}\right)^{2}+\mathrm{z}^{2}}} .
$$

A program was written to calculate the inductance matrix for each coil with respect to the others. The inductance of a single coil is the sum of all self-inductances and all mutual inductances of the individual turns (labelled k) with all the others (labelled l):

$$
L_{\text {ooil }}=\bigsqcup_{1}^{N} \bigsqcup_{1}^{N} L_{k l} .
$$

The same method can be employed for calculating the mutual inductances between coils.

For verifying the obtained results, FEA was used. In general, the inductance of a single coil can be obtained easily if the magnetic energy $\mathrm{W}_{\text {mag }}$ and current $\mathrm{I}$ in the conductor is known: 


$$
W_{\text {mag }}=\frac{1}{2} L_{\text {coil }} I^{2}
$$

Solving the above equation for $\mathrm{L}_{\text {coil }}$ yields

$$
L_{\text {coil }}=\frac{2 \cdot W_{m a g}}{I^{2}}
$$

The magnetic energy can be obtained easily by an FEA simulation, integrating the following expression over the complete model volume V:

$$
W_{\text {mag }}=\frac{\beta \cdot H}{2} d V
$$

For obtaining the mutual inductance between two coils, it is necessary to do two simulations: in the first simulation both coils are powered in the same direction, and in the second simulation the current in one coil is reversed. The inductances $\mathrm{L}_{\mathrm{ea}}$ and $\mathrm{L}_{\mathrm{eb}}$ for both arrangements is obtained using the above equations; the mutual inductance $\mathrm{L}_{\mathrm{ab}}$ can be calculated by [18];

$$
L_{a b}=\frac{L_{e a} \square L_{e b}}{4}
$$

Selected values of the mutual inductance and self-inductance were verified using this approach. It was found that the analytic code is in good agreement with the finite element results (of the order of 1-2 percent).

\section{b) Calculation of Inductance Networks for the MICE Magnet System}

Tables 6 and 7 show the inductance network for the MICE magnets with the coupling coils in series in the full flip and full non-flip modes. Intermediate mixed flip and non-flip cases are not included in the analysis. All of the information that is necessary to know about the inductive behavior of the magnets and the resultant coupling can be learned from studying the two extreme cases (and most likely operating cases). The diagonal between the upper left hand corner and the lower right hand corner of Tables 6 and 7 is the self-inductance of the magnet systems in question. The off diagonal terms are the mutual inductance terms between magnet systems.

Tables 8 and 9 show the inductance network for the MICE magnets with the coupling coils separately powered in the full flip and full non-flip modes. Intermediate mixed flip and non-flip cases are not included in the analysis. All of the information that is necessary to know about the inductive behavior of the magnets can be learned from the extreme cases. The diagonal between the upper left hand corner and the lower right hand corner of Tables 8 and 9 is the self-inductance of the magnet system in question. The off diagonal terms are the mutual inductance terms between magnet systems. 
Table 6. The Inductance Network for the MICE Magnets with the Three Focus Magnets in Series; the Two Coupling Magnets in Series; the Spectrometer Magnets (the two end coils and center coil in series) are in Series; and the Match Coils M1 and M2 in Series with their Corresponding Coils in the other Detector

Magnet. (This table applies when the MICE magnets are hooked up in the full flip mode.)

\begin{tabular}{|c|c|c|c|c|c|}
\hline & S & M2 & M1 & F & C1+C2 \\
\hline S & 172.2 & 1.503 & 0.859 & 0.206 & 0.614 \\
\hline M2 & 1.503 & 8.000 & 0.972 & 0.131 & 0.147 \\
\hline M1 & 0.859 & 0.972 & 32.60 & 1.293 & 0.487 \\
\hline F & 0.206 & 0.131 & 1.293 & 304.4 & 11.46 \\
\hline C1+C2 & 0.614 & 0.147 & 0.487 & 11.46 & 1178.4 \\
\hline
\end{tabular}

Table 7. The Inductance Network for the MICE Magnets with the Three Focus Magnets in Series; the Two Coupling Magnets in Series; the Spectrometer Magnets (the two end coils and center coil in series) are in Series; and the Match Coils M1 and M2 in Series with their Corresponding Coils in the other Detector Magnet. (This table applies when the MICE magnets are hooked up in the full non-flip mode.)

\begin{tabular}{|c|c|c|c|c|c|}
\hline & S & M2 & M1 & F & C1+C2 \\
\hline S & 172.5 & 1.505 & 0.873 & 0.766 & 0.906 \\
\hline M2 & 1.505 & 8.000 & 0.972 & 0.323 & 0.193 \\
\hline M1 & 0.873 & 0.972 & 32.60 & 2.439 & 0.625 \\
\hline F & 0.766 & 0.323 & 2.439 & 416.3 & 36.86 \\
\hline C1+C2 & 0.906 & 0.193 & 0.625 & 36.86 & 1206.8 \\
\hline
\end{tabular}

From Tables 6 and 7, it is clear that the inductance (both self inductances and mutual inductances are larger when the MICE magnet are hooked in the non-flip mode as compared to the full flip mode. The overall stored energy is larger for the magnets in the flip mode as compared to the non-flip mode when the magnets are powered to the same currents. From both Table 6 and Table 7, it is clear the coupling is largest between magnets that are close one another. Once one moves to a magnet circuit that as farther away, the mutual inductances go down. This is true in both the flip mode and the nonflip mode.

In Tables 6 and 7, the self-inductance diagonal squares are colored orange. The closest mutual inductance squares are colored a flesh color. The mutual inductance squares that are further away are not filled with color. The magnet system selfinductance is always highest when the magnets are hooked in the full non-flip mode. 
Table 8. The Inductance Network for the MICE Magnets with the Three Focus Magnets in Series. Each of the Two Coupling Magnets is Separately Powered. The Spectrometer Magnets (the two end coils and center coil in series) are in Series, and the Match Coils M1 and M2 in Series with their Corresponding

Coils. (This table applies when the MICE magnets are hooked up in the full flip mode.)

\begin{tabular}{|c|c|c|c|c|c|c|}
\hline & S & M2 & M1 & F & C1 & C2 \\
\hline S & 172.2 & 1.503 & 0.854 & 0.206 & 0.614 & 0.614 \\
\hline M2 & 1.503 & 8.000 & 0.972 & 0.131 & 0.147 & 0.147 \\
\hline M1 & 0.854 & 0.972 & 32.60 & 1.293 & 0.506 & 0.506 \\
\hline F & 0.206 & 0.131 & 1.293 & 304.4 & 5.731 & 5.731 \\
\hline C1 & 0.614 & 0.147 & 0.506 & 5.731 & 596.3 & 7.110 \\
\hline C2 & 0.614 & 0.147 & 0.506 & 5.731 & 7.110 & 596.3 \\
\hline
\end{tabular}

Table 9. The Inductance Network for the MICE Magnets with the Three Focus Magnets in Series Each of the Two Coupling Magnets is Separately Powered; the Spectrometer Magnets (the two end coils and center coil in series) are in Series; and the Match Coils M1 and M2 in Series with their Corresponding Coils.

(This table applies when the MICE magnets are hooked up in the full non-flip mode.)

\begin{tabular}{|c|c|c|c|c|c|c|}
\hline & S & M2 & M1 & F & C1 & C2 \\
\hline S & 172.5 & 1.505 & 0.873 & 0.766 & 0.906 & 0.906 \\
\hline M2 & 1.503 & 8.000 & 0.972 & 0.323 & 0.193 & 0.193 \\
\hline M1 & 0.873 & 0.972 & 32.60 & 2.439 & 0.806 & 0.806 \\
\hline F & 0.766 & 0.323 & 2.439 & 416.3 & 18.43 & 18.43 \\
\hline C1 & 0.614 & 0.193 & 0.806 & 18.43 & 596.3 & 7.110 \\
\hline C2 & 0.614 & 0.193 & 0.806 & 18.43 & 7.110 & 596.3 \\
\hline
\end{tabular}

In Tables 8 and 9, the self-inductance diagonal squares are colored orange. The closest mutual inductance squares are colored a flesh color. The squares with the mutual inductance between the two separate coupling coils are colored a lime color. The mutual inductance squares that are further away are not filled with color. The magnet system self-inductance is always highest when the magnets are hooked in the full non-flip mode.

From Tables 8 and 9, it is clear that each of the coupling coils is coupled to the other magnets circuits in MICE the same way. The self-inductance of the coupling coils circuits is lower (by about a factor of two) when the coils are powered separately. The mutual inductance between the separate coils and other circuits are also lower. 
The charging voltage for a magnet coil system $\mathrm{V}_{\mathrm{ch}}$ for a given $\mathrm{di}_{1} / \mathrm{dt}$ can be calculated using the following equation, when there is resistance in the circuit;

$$
V_{c h}=L_{1} \frac{d i_{1}}{d t}+R_{m} i_{1}
$$

where $L_{1}$ is the self-inductance of the magnet circuit; $i_{1}$ is the current in the magnet circuit that is being charged and $R_{m}$ is the resistance of the circuit. The voltage induced in a second magnet circuit $\mathrm{V}_{2}$ that is inductively coupled to the first magnet circuit that is being charged or discharged at the can be calculated using the following expression;

$$
V_{2}=\square M_{1 \square 2} \frac{d i_{1}}{d t}
$$

where $\mathrm{M}_{1-2}$ is the mutual inductance between circuit 1 and circuit $2 ; \mathrm{di}_{1} / \mathrm{dt}$ is the rate of current change in circuit 1.

Since every magnet in MICE is coupled to every other magnet in MICE on can se the effect of charging or discharging a magnet circuit on the other magnets circuits in MICE through the mutual inductance terms that are given in Tables 6 through 9. In general, a voltage that is induced in the other circuits due to the charging of the first magnet circuit is substantially lower than the charging voltage on the first circuit. Charging will not be a problem provided the power supply can develop both positive and negative voltage to counter the effect of mutual inductance between the various circuits.

A magnet quench may be another matter. Suppose the magnets in circuit 1 quench causing values of $\mathrm{di}_{1} / \mathrm{dt}$ from 50 to $100 \mathrm{~A} \mathrm{~s}^{-1}$. Closely coupled circuits may see voltages across the leads as high as $3.6 \mathrm{kV}$. (See the coupling between the focus coils and a pair of coupling coils in the non-flip mode in table 7 when $\mathrm{di} / \mathrm{dt}=100 \mathrm{~A} \mathrm{~s}^{-1}$.) For a short period of time (say a maximum of 3 seconds) the rate of change of the current may be 360 times that generated by the power supply. Whether this change in the current quenches the magnet coupled to the magnet quenching depends on how much temperature margin exists in the second superconducting magnet. Even if there is plenty of temperature margin in the superconducting coil, current induced in the mandrel may cause a quench.

The charge time $t_{c h}$ for a magnet circuit can be estimated using the following expression, which includes the resistance of the magnet circuit leads between coils and between the power supply and the coils $\mathrm{R}_{\mathrm{m}}$;

$$
t_{c h}=\frac{2 L_{1}}{\left(2 V_{P S} \square R_{m} i_{\max }\right)} i_{\max }
$$

where $\mathrm{L}_{1}$ is the self-inductance of the magnet circuit being charged; $\mathrm{V}_{\mathrm{PS}}$ is the power supply voltage; $\mathrm{R}_{\mathrm{m}}$ is the resistance of the magnet circuit; and $\mathrm{I}_{\max }$ is the maximum current in the magnet circuit at the end of the charge. (In general, the magnet circuit should be designed so that $R_{m} i_{\max }=2$ to 3 volts.) If the power supply voltage $V_{P S}$ is set at $10 \mathrm{~V}$, the average voltage across the magnet circuit will be from 8.5 to $9.0 \mathrm{~V}$. Using equation 43 , one can estimated the charging time for a $10 \mathrm{~V} 300$ A power supply. If one looks at worst case, one finds that the non-flip case shown in Table 7 is the case that will yield the longest charge time for both the coupling and focusing magnet circuits. The two match coil charge times and the spectrometer magnet charge times will be shorter in all cases. 


\section{Magnet Power Supply Design Parameters}

The two parameters that determine the size of the power supply are; 1) the maximum current seen by the magnet circuit in all MICE operating modes, and 2) the desired charge and discharge time for the magnet circuits.

In terms of the magnet circuit current, the maximum current seen by any of the MICE magnet circuits is between 240 and 290 A. The maximum power supply current is set at 300 A. A charge and discharge time for the mice magnets must be reasonable. Since the experiment will run for days at the same current setting a definition of reasonable might be as large as 18000 seconds ( 5 hours). The longest charge time would be for a pair of coupling coils in series in the non-flip mode. If the power supply voltage is set at $10 \mathrm{~V}$ and the maximum voltage drop for the leads is $3 \mathrm{~V}$, the charge time for the coupling magnet would be about 30212 second ( 8.42 hours). The next longest charge time is for three focusing magnets in series in the no-flip mode, which is $12300 \mathrm{~s}$ (about 3.4 hours). If a charging time of 4 to 5 hours is reasonable, the maximum power supply voltage can be set to $10 \mathrm{~V}$ and each coupling magnet must have a separate power supply.

The current ripple and the current regulation are the other important factors for the MICE magnet power supplies. In general, the current delivered by the power supply must be accurate to 0.1 percent. In general it is a good idea to set both the maximum current ripple and the maximum current regulation error to less than 0.03 percent. It is recommended that the power supply be a three-phase power supply. If the power supply is a three-phase power supply the voltage ripple will be less than two percent at a frequency of $720 \mathrm{~Hz}$, for a $60 \mathrm{~Hz}$ power source and $600 \mathrm{~Hz}$ for a $50 \mathrm{~Hz}$ power source. Since all of the MICE magnet circuits have a high inductance, the current ripple will be two or three orders of magnitude less than the voltage ripple.

The power supply should be capable of generating both a positive and a negative voltage of $10 \mathrm{~V}$, in order to achieve the degree of control needed for the MICE magnets. The power supply need only produce a positive current that is controlled to 0.03 percent. Table 10 presents the parameters for both the main power supplies and the current adjustment power supplies. The number of power supplies quoted assumes a single supply for all focusing magnets, on power supply each for the coupling magnets, and three power supplies for the detector magnets.

Table 10. Power Supply Parameters for the MICE Magnet Power supplies

\begin{tabular}{|l|c|c|}
\hline \multicolumn{1}{|c|}{ Parameter } & Main Supply & Control Supply \\
\hline Number of Power Supplies for MICE* & $\mathbf{6}$ & $\mathbf{6}$ \\
\hline Maximum Supply Design Voltage (V) & $\mathbf{+ 1 0}$ & $\mathbf{+ 1 0}$ \\
\hline Minimum Supply Design Voltage (V) & $\mathbf{- 1 0}$ & $\mathbf{- 1 0}$ \\
\hline Maximum Supply Design Current (A) & $\mathbf{+ 3 0 0}$ & $\mathbf{+ 5 0}$ \\
\hline Minimum Supply Design Current (A) & $\mathbf{0}$ & $\mathbf{0}$ \\
\hline Voltage Ripple Frequency in UK (Hz) & $\mathbf{6 0 0}$ & $\mathbf{6 0 0}$ \\
\hline Max Allowable Current Ripple (\%) & $\mathbf{0 . 0 3}$ & $\mathbf{0 . 0 3}$ \\
\hline Max Allowable Regulation Error (\%) & $\mathbf{0 . 0 3}$ & $\mathbf{0 . 0 3}$ \\
\hline
\end{tabular}

* The number of small power supplies includes two control power supplies for the focusing coils at the ends of the MICE cooling channel. The number of power supplies given does not include spares. 


\section{Magnet Quench Back due to Inductive Coupling to the Mandrels}

\section{a) Quench back from the Mandrel - Simulation Calculation Details}

For the quench-back simulations, two coupled FEA simulations are used. One simulation is necessary for obtaining the magnetic fields and induced eddy currents (electromagnetic simulation), whereas the second calculates the heat in the support structure of the MICE channel (heat transfer simulation). Both simulations are coupled using coupling variables; in particular, the induced currents in the aluminum structure are transferred to the heat transfer simulation, necessary for obtaining the heating.

The electromagnetic simulation is based on the so called quasi-static assumption, which assumes that the displacement currents are negligible (which is valid if the finite speed of light is negligible and the magnetic field can be regarded to propagate instantaneously [22]). The equation [20] solved is;

$$
\square \frac{\partial A}{\partial t}+\square \square\left(\square_{0}^{\square !} \square \square A \square M\right) \square \square v \square(\square \square A)+\square V=J^{e}
$$

where $\mathrm{A}$ is the vector potential, $\mathrm{M}$ the magnetization vector, _ the electric conductivity, $\mathrm{V}$ the electric potential, $v$ the velocity of the conductor and $\mathrm{J}^{\mathrm{e}}$ an external current density. For obtaining the temperature in the aluminum structure, the heat equation is solved [21]:

$$
Q=\square C \frac{\partial T}{\partial t} \square \square \cdot(k \square T)
$$

where $\mathrm{Q}$ is a heat source, $\mathrm{C}$ the specific heat, - the density of the material, $\mathrm{T}$ the temperature and $\mathrm{k}$ the heat conductivity. The heat is generated by the induced eddy currents $\mathrm{J}_{\text {induced }}$; the term used for $\mathrm{Q}$ is;

$$
Q=\frac{J_{\text {induced }}^{2}}{\square} .
$$

Both FEA models are solved simultaneously, which means that changes in the material properties during the simulation time because of a temperature variation can be taken into account. All relevant material properties, namely the heat conductivity and specific heat are varied as a function of the temperature. For the electric conductivity a value of $\square=7.1 \times 10^{7} \mathrm{~S} / \mathrm{m}\left(\square=1.4 \times 10^{-8} \square \mathrm{m}\right)$ is used as the conductivity of 6061 aluminum below $75 \mathrm{~K}$. The conductivity varies very little (about $10 \%$ ). For $\mathrm{T}<25 \mathrm{~K}$ a value of $8 \mathrm{~J} / \mathrm{kg} / \mathrm{K}$ was used for the heat capacity. The material properties are obtained from [19]. The expressions used for the specific heat and the heat conductivity are;

$$
\begin{array}{ll}
C(T) & =911+\frac{(-525-911)}{1+\mathrm{e}^{(\mathrm{T}-55) / 57}} \frac{J}{\mathrm{~kg} \cdot \mathrm{K}} \text {, and } \\
\mathrm{K}(T) & =1.73 \cdot \mathrm{T} \frac{\mathrm{W}}{\mathrm{m} \cdot \mathrm{K}}
\end{array}
$$


For the quench simulation it was assumed that the current in the coils of the magnetic channel decay in a linear manner. The current densities used can be taken from the following table.

Table 11. The Current Densities in the Magnet Coils used for the Quench Back Simulations

\begin{tabular}{|l|c|c|}
\hline \multirow{2}{*}{ Magnet } & \multicolumn{2}{|c|}{ Coil Current Density $\left(\mathrm{A} \mathrm{mm}^{-2}\right)$} \\
\cline { 2 - 3 } & Flip Mode & Non-flip Mode \\
\hline Focusing Magnet & $\mathbf{1 3 6 . 7 4}$ & $\mathbf{7 1 . 4 2}$ \\
\hline Coupling Magnet & $\mathbf{1 1 5 . 4 5}$ & $\mathbf{1 0 4 . 8 9}$ \\
\hline
\end{tabular}

It was assumed that the current in the focusing coil and coupling coil decay within four and five seconds, respectively.

\section{b) Mandrel Temperature due to Quenching of the Coil wound on that Mandrel}

A magnet can quench back from its own mandrel, if the magnet is discharged quickly. This is illustrated for the focusing coil in Figures 14 through 17, which show the temperature of the magnet mandrel after the current decay time of 4 seconds.

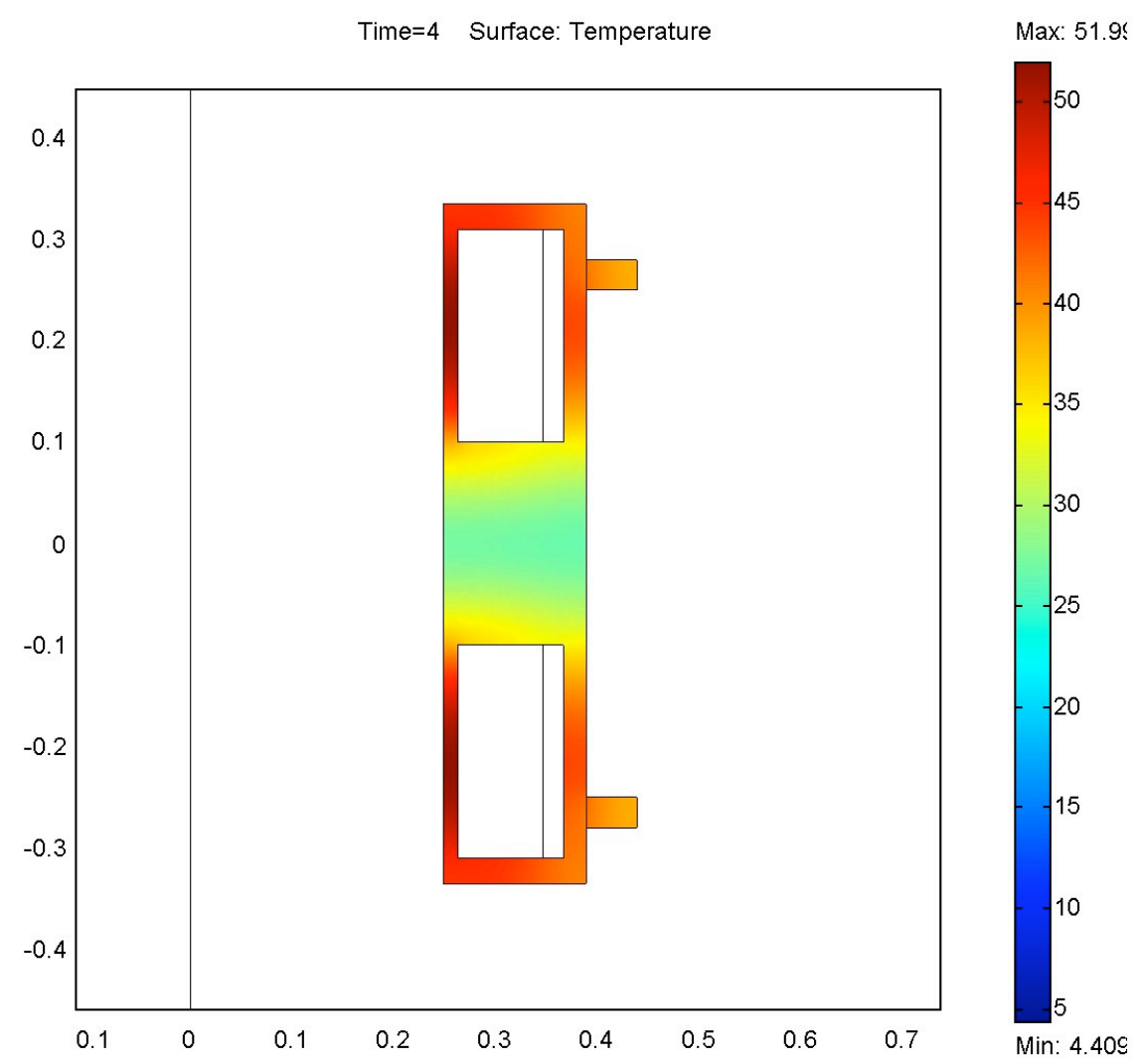

Figure 14. The Temperature of the Focusing Magnet Mandrel after the Magnet Current Decayed from 250.7 A to zero in 4 seconds (The magnet is operating in the flip mode.) 
Figure 14 shows the temperature distribution in the focusing coil mandrel after the magnet was discharged in 4 seconds. The magnet was operating in the flip mode, with the coils operating at opposite polarity. The hottest point on the mandrel is under the coil at a point that is very close to the high field point of the magnet. This region is very closely coupled to the superconducting coil. The section of the mandrel that is between the coils is inductively much less well coupled to coils. As a result, the mandrel temperatures are much lower in this region. Heat transfer between various parts of the mandrel is included in the calculations shown in Figure 14.

Figure 15 shows the axially symmetric temperature distribution after the focusing magnet has been discharged in 4 seconds. The temperature plot shown in Figure 15 was for when the magnet was operated in the non-flip mode (the solenoid mode).

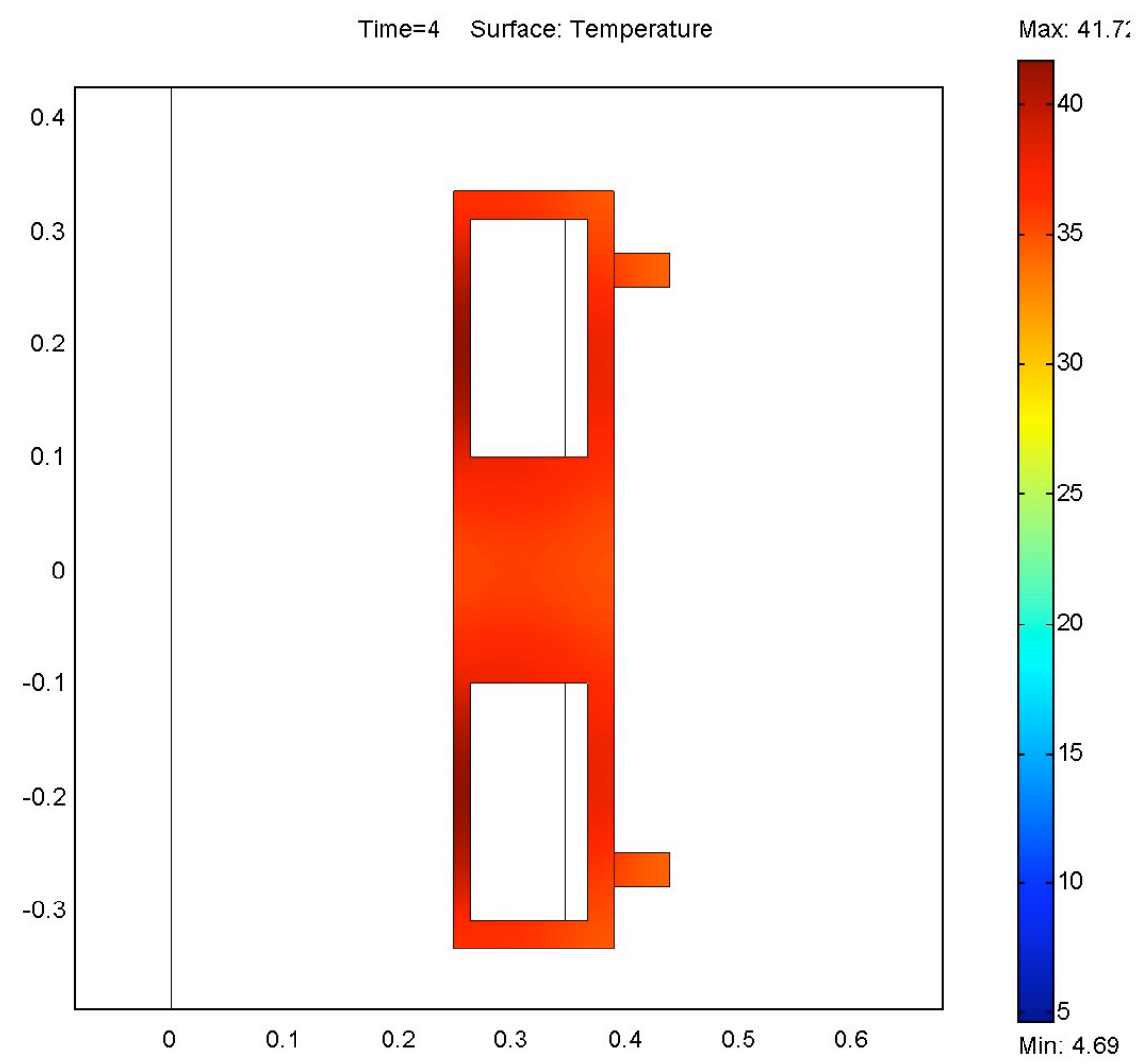

Figure 15. The Temperature of the Focusing Magnet Mandrel after the Magnet Current Decayed from 130.7 A to zero in 4 seconds (The magnet is operating in the non-flip mode.)

When the focusing magnet is discharged in 4 seconds after being operated in the non-flip mode, the temperature distribution within the mandrel is more uniform. (The temperature range in the mandrel for the non-flip case is from $36 \mathrm{~K}$ to $41 \mathrm{~K}$ versus a temperature range from $25 \mathrm{~K}$ to $52 \mathrm{~K}$ for the flip case.) All of the mandrel seeing the changing flux in the non flip mode. The lower average temperature of the mandrel reflects the lower initial stored energy of the magnet when operated in the non-flip mode (about $1.3 \mathrm{MJ}$ versus $3 \mathrm{MJ}$ ).

Figure 16 shows the temperature at the hot spot in the focusing coil mandrel as a function of time. The temperature rise from 4.2 to $25 \mathrm{~K}$ occurs in less than 0.6 seconds. The time for the mandrel hot spot to reach $9 \mathrm{~K}$ is less than 0.2 seconds. This time is much shorter than the quench back time calculated using Equation 35 (1.06 seconds), 
which is based upon a growth the resistance with time. Much of the time is spent in a regime where di/dt is $<<62.5 \mathrm{~A} \mathrm{~s}^{-1}$. When $t=1 \mathrm{~s}$, the value of di/dt $=\sim 50 \mathrm{~A} \mathrm{~s}^{-1}$. Figure 17 shows the temperature at the hot spot in the focusing coil as a function of time. The time to reach $25 \mathrm{~K}$ and $9 \mathrm{~K}$ is longer because there is less di/dt producing the heat.

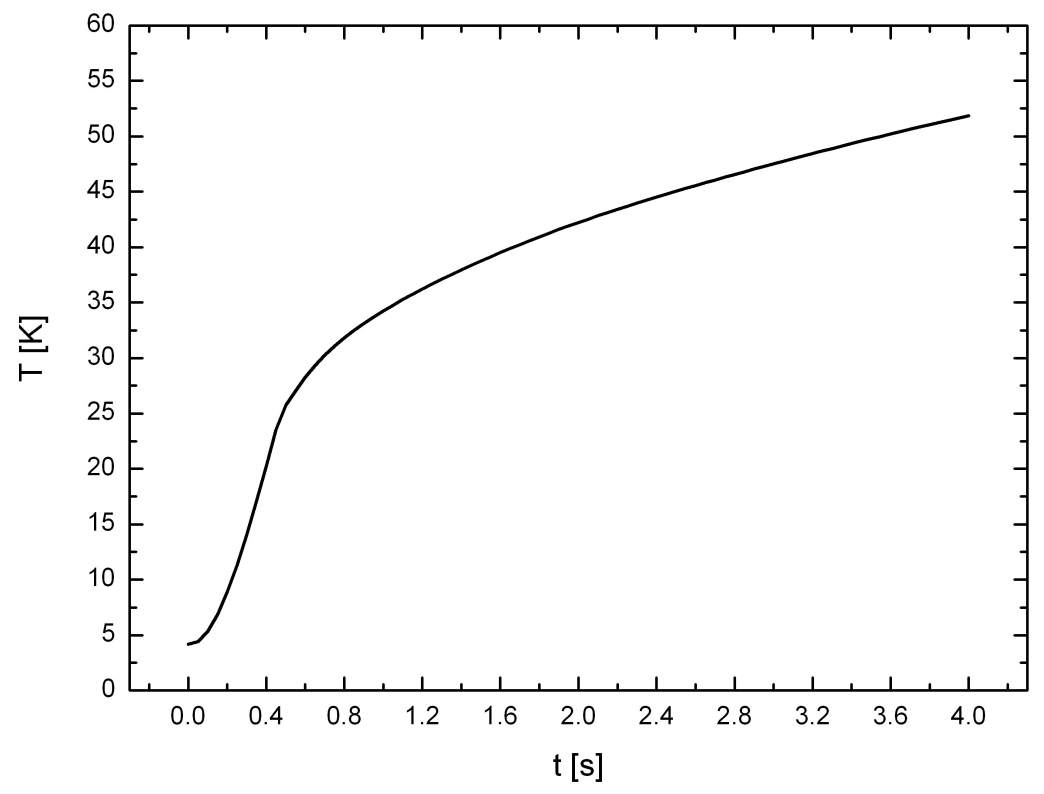

Figure 16. The Temperature of the Focusing Magnet Mandrel Hot Spot as a Function of Time when the Magnet Current Decayed from 250 A to zero in 4 seconds (The magnet is operating in the flip mode.)

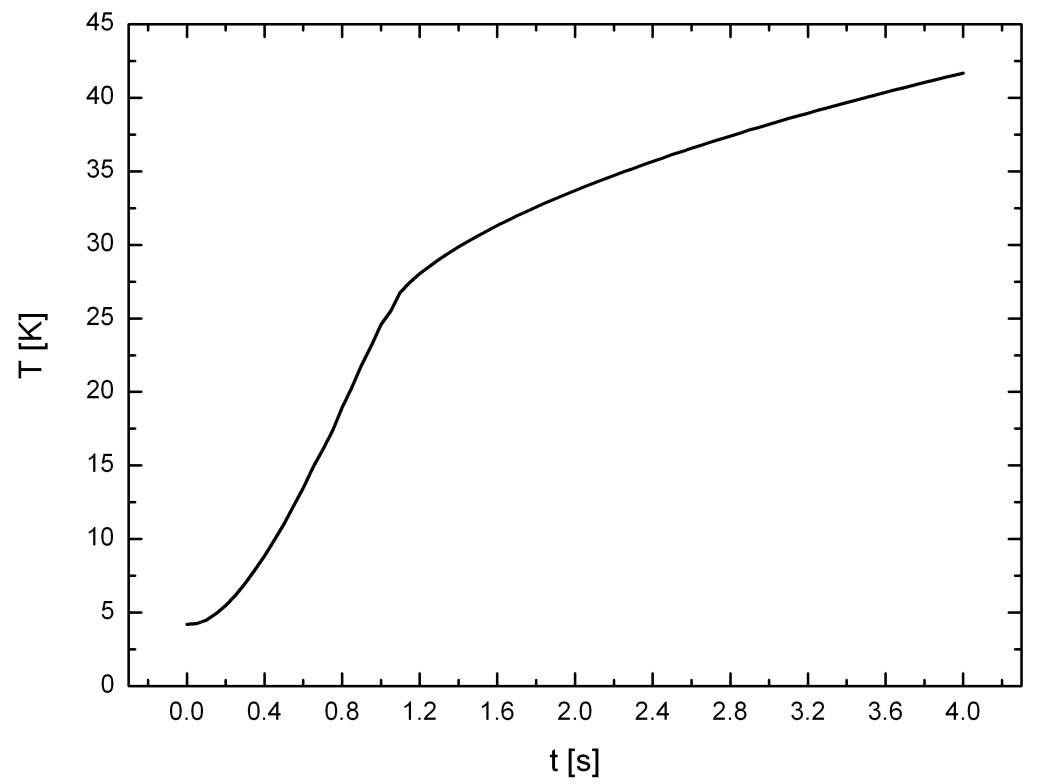

Figure 17. The Temperature of the Focusing Magnet Mandrel Hot Spot as a Function of Time when the Magnet Current Decayed from 250 A to zero in 4 seconds (The magnet is operating in the non-flip mode.) 


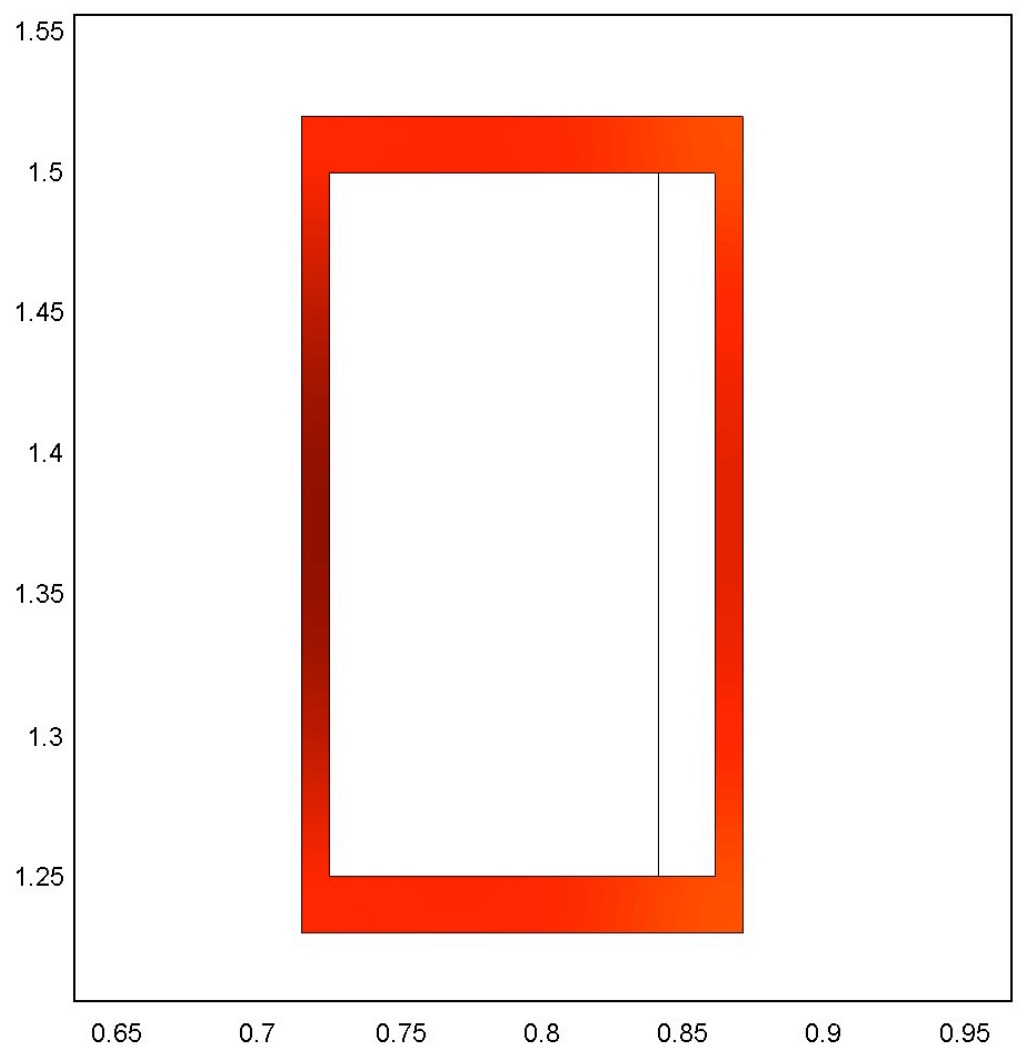

Figure 18. The Temperature of the Coupling Magnet Mandrel after the Magnet Current Decayed from 213 A to zero in 5 seconds

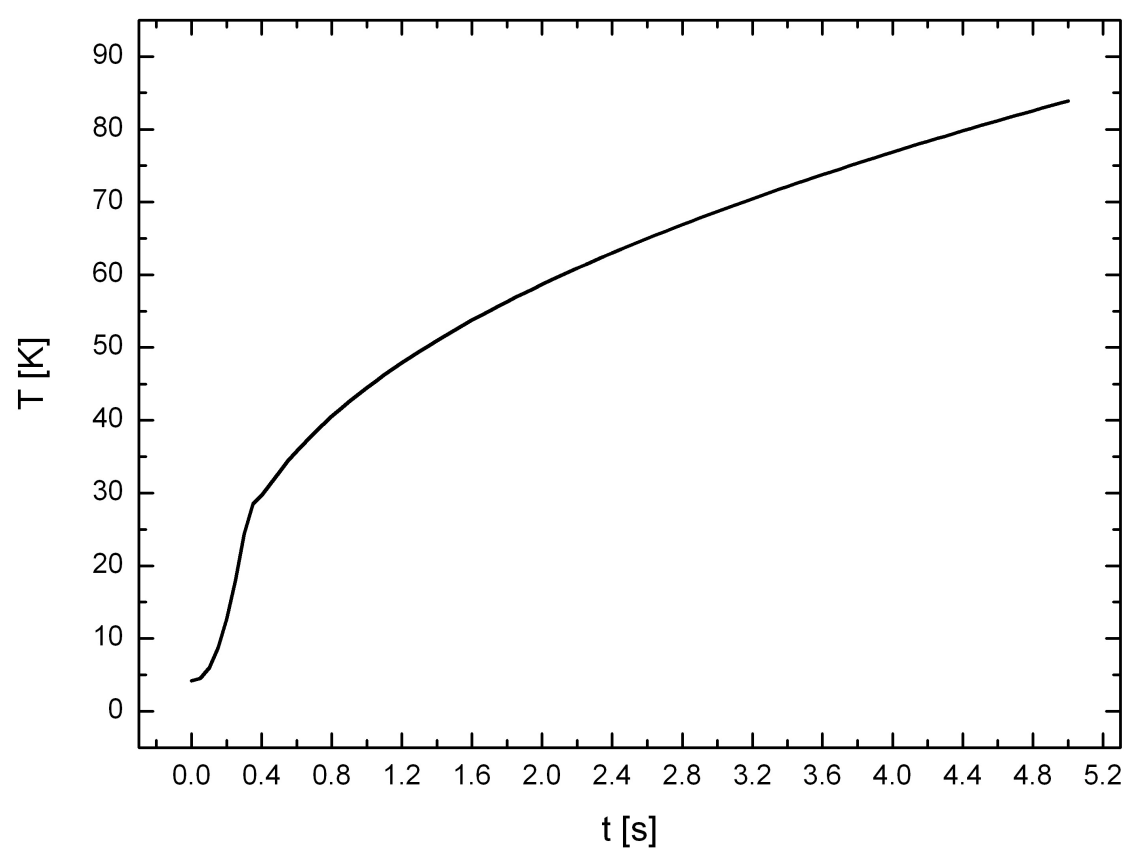

Figure 19. The Temperature of the Coupling Magnet Mandrel Hot Spot as a Function of Time when the Magnet Current Decayed from 213 A to zero in 5 seconds 
Figure 18 shows the temperature distribution in the mandrel of the coupling magnet after a current decay from $213 \mathrm{~A}$ to zero in 5 seconds. (The di/dt $=42.6 \mathrm{~A} \mathrm{~s}^{-1}$ ). The temperature across the mandrel is quite uniform (from $69 \mathrm{~K}$ to $84 \mathrm{~K}$ ). All of the mandrel is well coupled with the coil. The average coupling coefficient for the entire mandrel with the entire coupling coil is of the order of 92 percent. The increased temperature of the mandrel reflects the larger stored energy within the coupling magnet.

When one look at Figure 19, one can see a rapid increase in the mandrel hot spot temperature (from $4.2 \mathrm{~K}$ to $25 \mathrm{~K}$ in about 0.4 seconds). The temperature reaches $9 \mathrm{~K}$ in less than 0.2 seconds. This time is much less than the 2.17 seconds for the quench back time calculated using Equation 35. As with the focusing magnet, it should be remembered that Equation 35 assumes a growth in the magnet resistance with time. It takes over 5 seconds before di/dt reaches $40 \mathrm{~A} \mathrm{~s}^{-1}$, which only occurs after quench back has occurred and the whole coil has gone normal.

\section{c) Mandrel Temperature due to Quenching of a Coil wound on another Mandrel}

The quenching on one magnet can cause a second magnet to quench through quench back. Whether a one quenching magnet can cause a quench in another magnet depends on a number of factors that include; 1) the coupling coefficient between the mandrel inducing the quench and the coil that is (coils that are) quenching, 2) the temperature margin of the magnet being quenched through quench back, and 3) the thermal time constant for the heat entering the coil from the mandrel.

In general, the thermal time constant is small compared to the time that it takes to raise the mandrel temperature enough to induce quench back in a coil that is wound on that mandrel. The coupling coefficient and the temperature margins appear to be the most important factors in determining whether a quench in one magnet system causes and adjacent magnet system to quench through quench back from the mandrel. The coupling coefficient $\square$ may be calculated using the flowing expression [16]:

$$
\square=\frac{L_{1} L_{2}}{M_{1 \square 2}^{2}}
$$

where $\mathrm{L}_{1}$ is the self-inductance of the primary circuit (the magnet system that is quenching); $\mathrm{L}_{2}$ is the self-inductance of the secondary circuit (the mandrel of the second magnet); and $\mathrm{M}_{1-2}$ is the mutual inductance between the two circuits.

Table 12 shows four cases that are of interest in terms of whether the quenching of one magnet system causes quenching of adjacent magnets. The value of $\square$ in Table 12 should be compared to the estimated coupling coefficients for the magnets with their own mandrels. ( $\square=0.82$ for the focusing magnet; $\square=0.92$ for the coupling magnet.)

Table 12. The Coupling Coefficient for Various Primary Magnet Systems with Various Mandrels

\begin{tabular}{|c|c|c|}
\hline Primary & Secondary & $\square$ \\
\hline 2 Coupling & Focusing Mandrel & $\mathbf{0 . 0 0 8 1 3}$ \\
\hline 1 Coupling & Focusing Mandrel & $\mathbf{0 . 0 0 4 1 2}$ \\
\hline 3 Focusing Flip & Coupling Mandrel & $\mathbf{0 . 0 0 0 1 8}$ \\
\hline 3 Focusing Non-flip & Coupling Mandrel & $\mathbf{0 . 0 0 1 3 7}$ \\
\hline
\end{tabular}



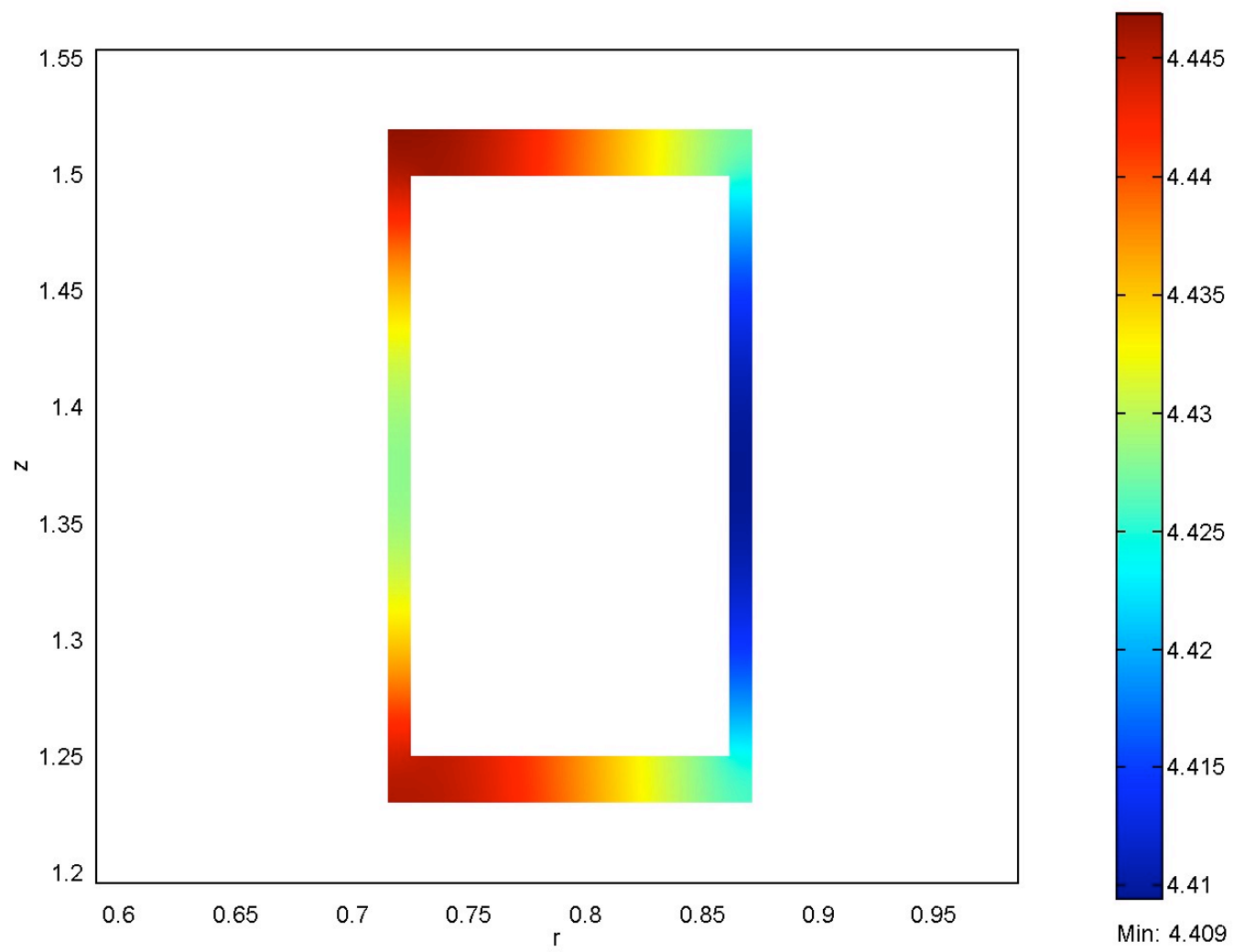

Figure 20. The Temperature of the Coupling Magnet Mandrel after the Current in Three Focusing Magnets in the Flip Mode has decayed from 250 A to zero in 4 seconds

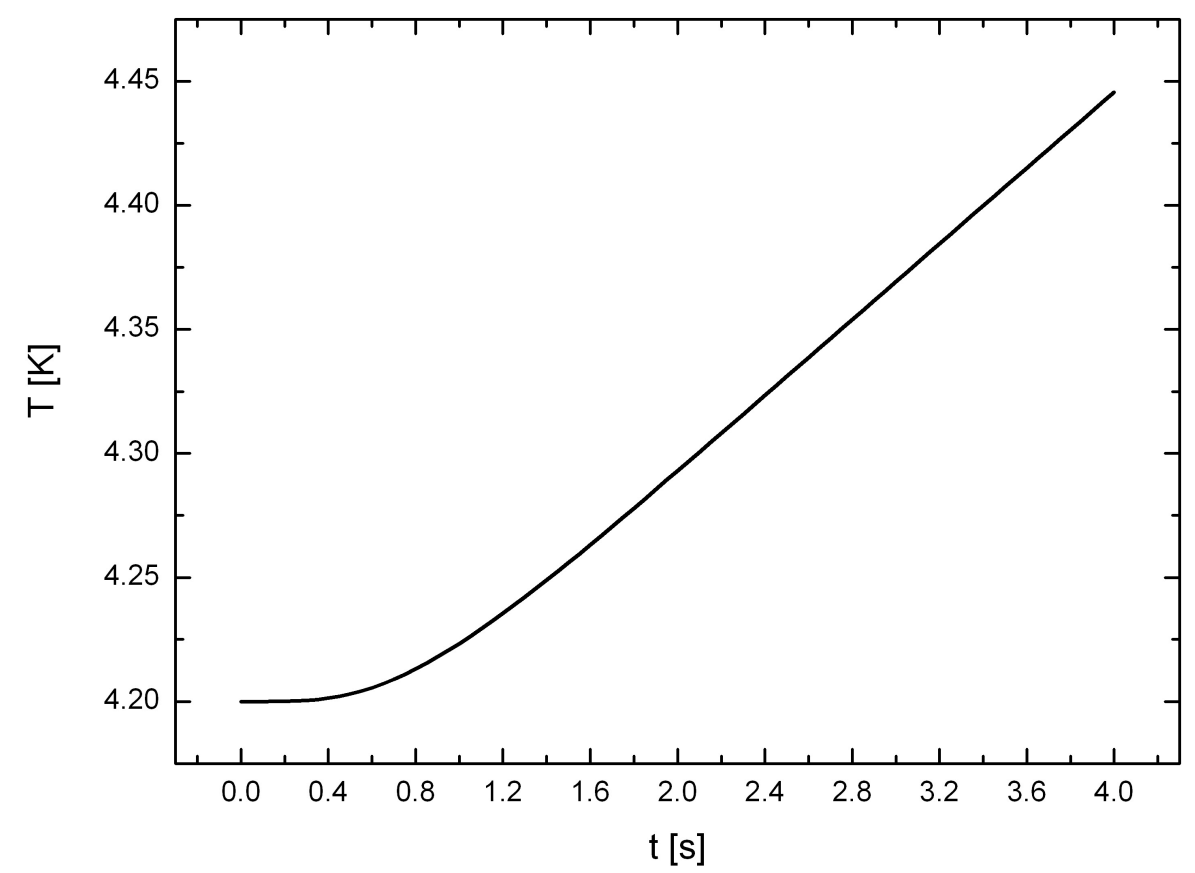

Figure 21. The Temperature of the Coupling Magnet Mandrel Hot Spot as a Function of Time when the Current in Three Focusing Magnets in the Flip Mode has decayed from 250 A to zero in 4 seconds 

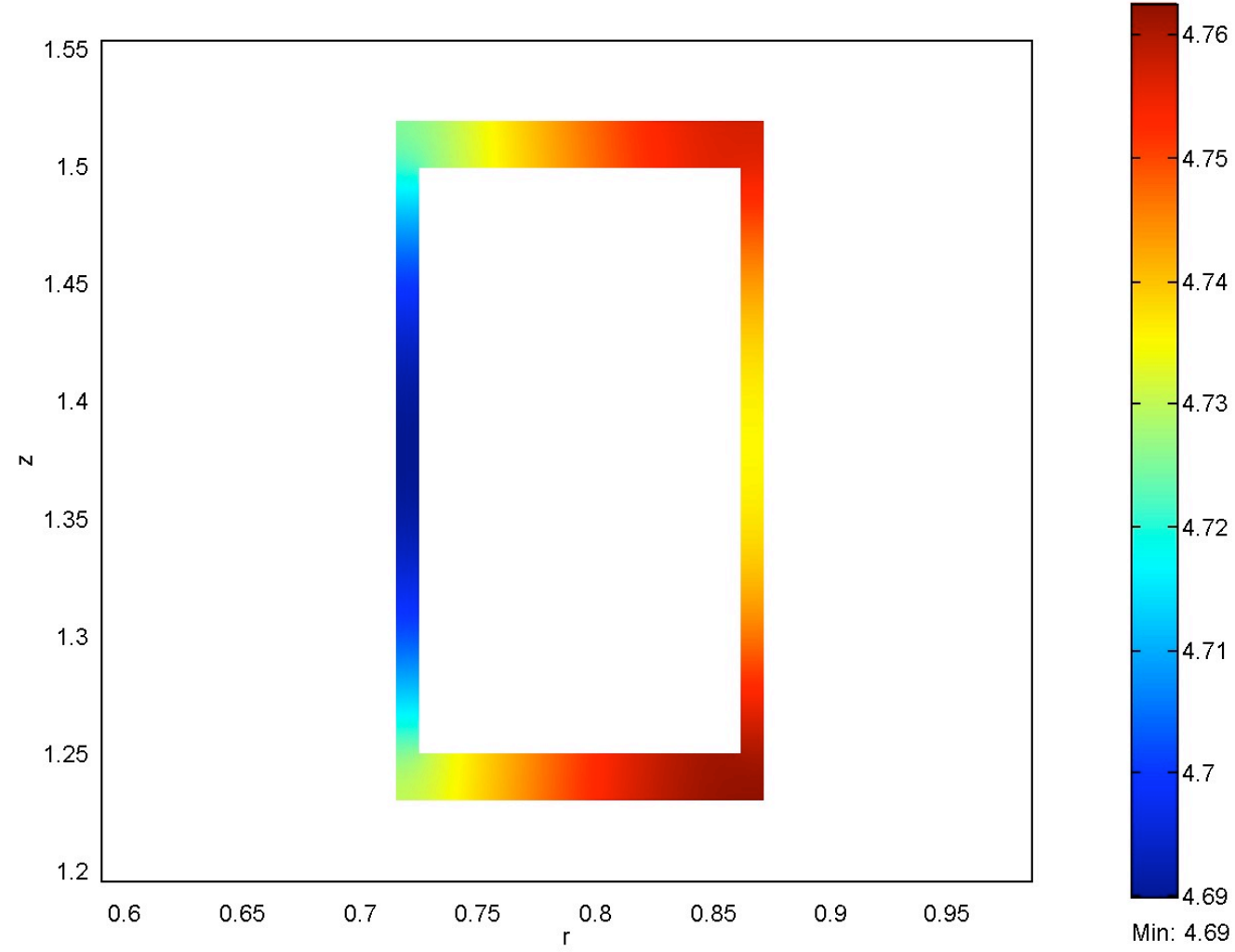

Figure 22. The Temperature of the Coupling Magnet Mandrel after the Current in Three Focusing Magnets in the Non-flip Mode has decayed from 130 A to zero in 4 seconds

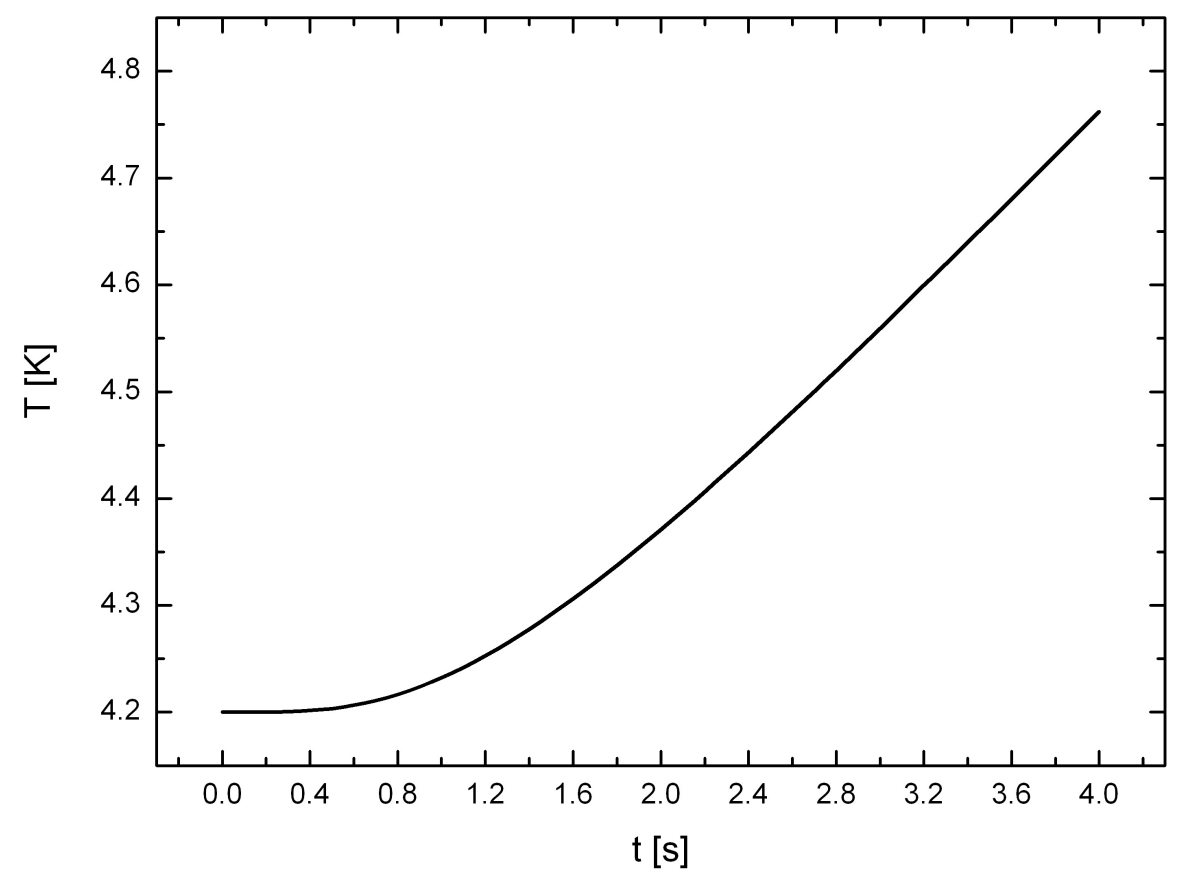

Figure 23. The Temperature of the Coupling Magnet Mandrel Hot Spot as a Function of Time when the Current in Three Focusing Magnets in the Non-flip Mode has decayed from 130 A to zero in 4 seconds 


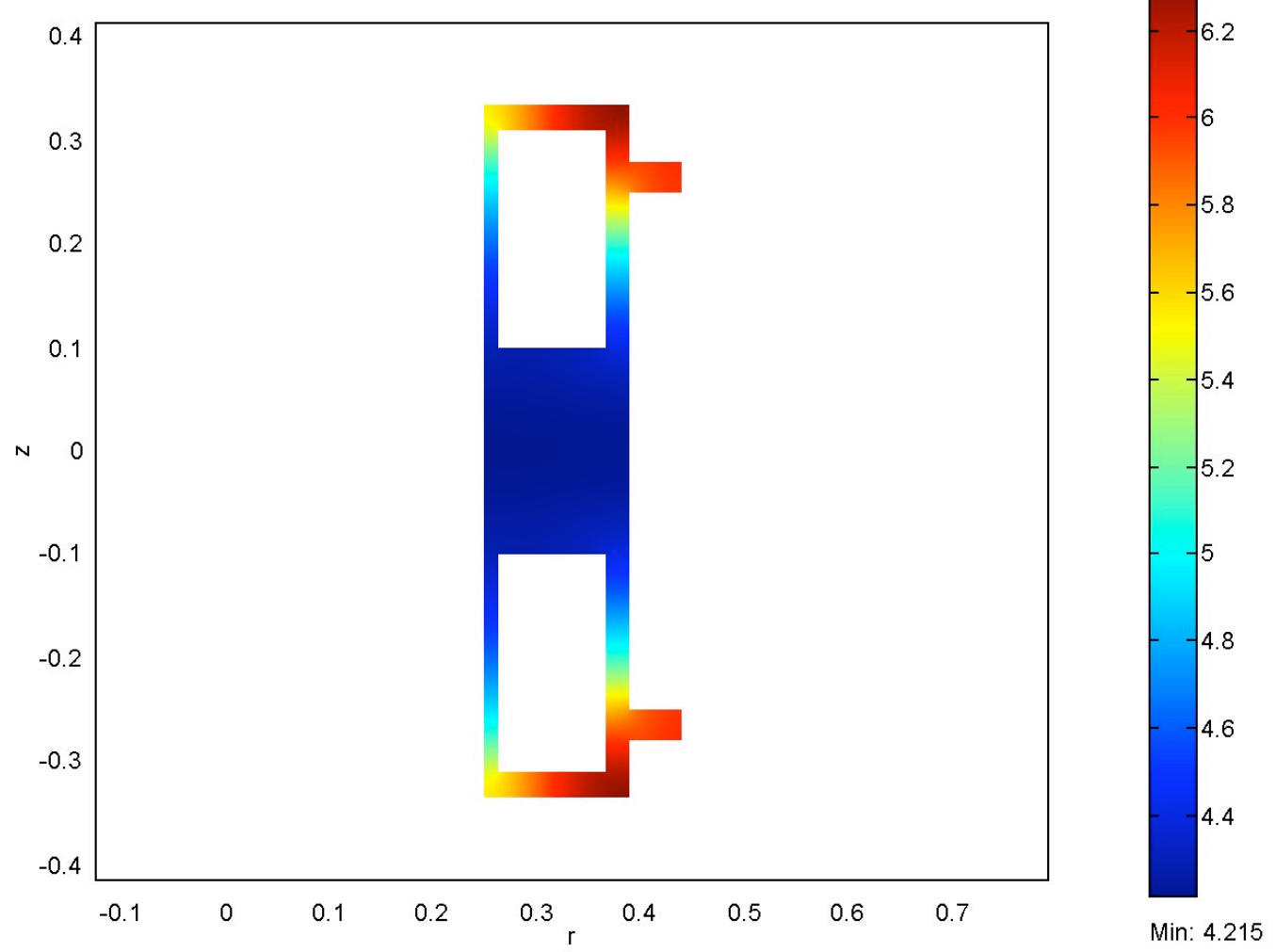

Figure 24. The Temperature of the Focusing Magnet Mandrel after the Coupling magnet Current Decayed from 213 A to zero in 5 seconds (The magnet is operating in the flip mode.)

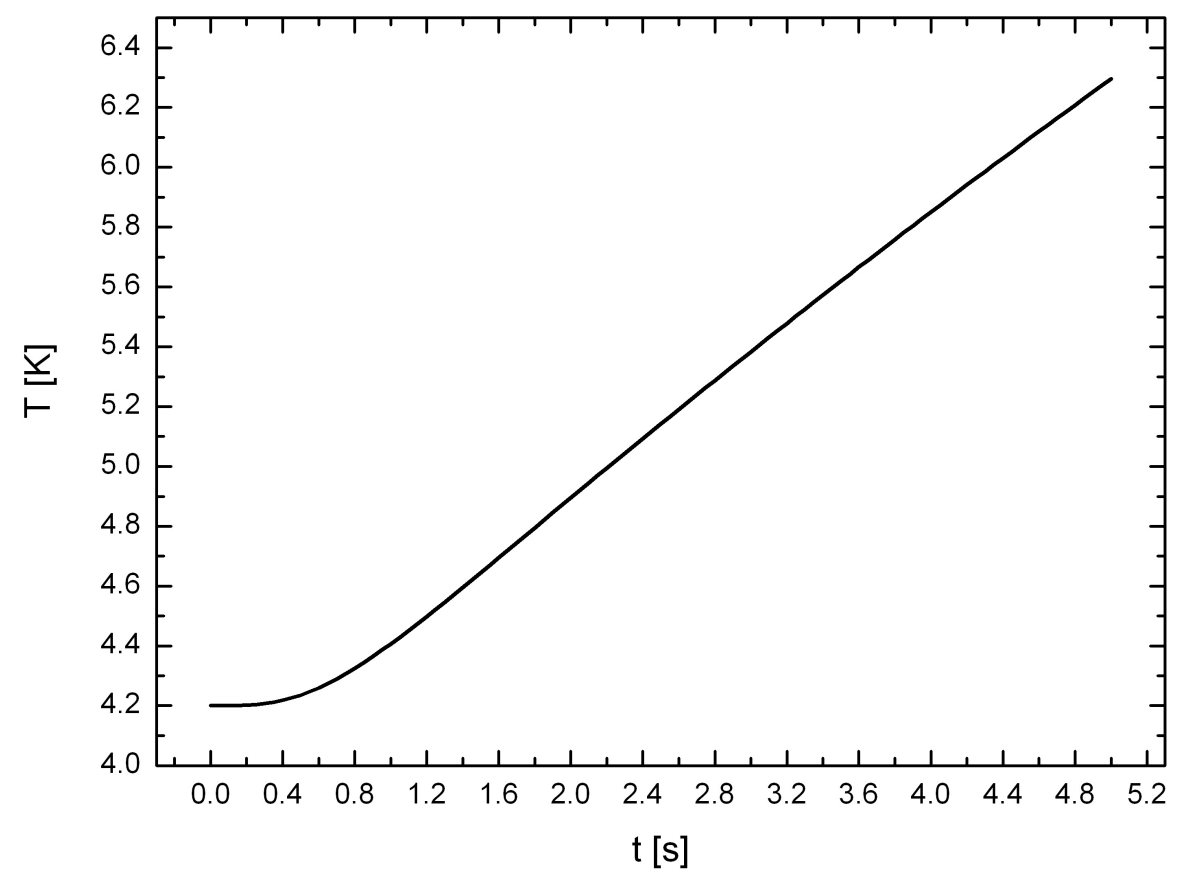

Figure 25. The Temperature of the Focusing Magnet Mandrel Hot Spot as a Function of Time when the Coupling Magnet Current Decayed from 213 A to zero in 5 seconds (The magnet is in the flip mode.) 
Figures 20 through 25 illustrate the effect of coupling between a focusing magnet and a coupling magnet on the mandrel of the magnet of the other type. Figure 20 shows the temperature distribution in the coupling magnet mandrel due to a 4 second current decay (from 250 A to zero) in three focusing magnets in series in the flip mode. The peak temperature in the coupling coil mandrel is $4.45 \mathrm{~K}$. The estimated coupling coefficient for this case is 0.00018 . The high temperature point in the coupling coil mandrel is on the inner corners. This point is close to the high field point in the coupling magnet. Figure 21 shows the temperature at the hot spot as a function of time for the case shown in Figure 20. It can be concluded that a quench in three focusing magnets in series, in the flip mode, is unlikely to cause a quench in the coupling magnet due to quench back.

Figure 22 shows the temperature distribution in the coupling magnet due to a 4 second current decay (from 130 A to zero) in three focusing magnets in series in the nonflip mode. The peak temperature in the coupling coil mandrel is $4.73 \mathrm{~K}$. The increased mandrel temperature in the non-flip case reflects the larger estimated coupling coefficient of 0.00137. The high temperature point occurs on the outer corners of the coupling coils. The temperature in the mandrel near the high field point is lower, but not very much lower. Figure 23 shows the temperature at the hot spot as a function of time for the case shown in Figure 22. It can be concluded that a quench in three focusing magnets in series, in the non-flip mode, is unlikely to cause a quench in the coupling magnet due to quench back, except for cases where the beam $\square$ is low in the absorber and the current his high in the focusing magnets due to the increased average momentum of the muon beam.

Figure 24 shows the temperature distribution in the focusing magnet mandrel due to a 5 second current decay (from 213 A to zero) in the coupling magnets in series in the flip mode. The peak temperature in the coupling coil mandrel is $6.30 \mathrm{~K}$. The increased mandrel temperature in the non-flip case reflects the larger estimated coupling coefficient of 0.00813. It is interesting to note that the hot spot in the focusing magnet mandrel is on the outside corner of the mandrel. This point is well away from the high field point of the magnet, so the effect of the higher temperature is not so severe, because the temperature margin for the coil near the hot spot is much larger. Figure 25 shows the temperature at the hot spot as a function of time for the case shown in Figure 24. It can be concluded that a quench of two coupling magnets in series, in the non-flip mode, is likely to cause a quench in the focusing magnet due to quench back from the mandrel, except for cases where the average momentum is low.

Table 13. The Coupling Coefficient for Other Primary Magnet Systems with Various Other Mandrels

\begin{tabular}{|c|c|c|}
\hline Primary & Secondary & $\square$ \\
\hline 1 Coupling Non-flip & Match 1 Mandrel & $\mathbf{0 . 0 0 0 0 3}$ \\
\hline 1 Coupling Non-flip & Spectrometer Mandrel & $\mathbf{0 . 0 0 0 4 0}$ \\
\hline 3 Focusing Flip & Match 1 Mandrel & $\mathbf{0 . 0 0 0 3 4}$ \\
\hline 3 Focusing Non-flip & Match 1 Mandrel & $\mathbf{0 . 0 0 0 8 8}$ \\
\hline 3 Focusing Non-flip & Spectrometer Mandrel & $\mathbf{0 . 0 0 0 4 1}$ \\
\hline 2 Match 1 Non-flip & Focusing Mandrel & $\mathbf{0 . 0 0 1 3 2}$ \\
\hline 2 Spectrometer Non-flip & Focusing Mandrel & $\mathbf{0 . 0 0 0 0 3}$ \\
\hline
\end{tabular}


From Table 13 it is clear that coupling between the cooling channel magnets (the focusing and coupling magnets) and the detector magnets is small. Since the temperature margin for all of the detector magnets is large (about $2 \mathrm{~K}$ ), it is unlikely that any of the detector magnet circuits will be driven normal through quench back from the mandrel. From Table 13 it is also clear that quenching the spectrometer magnet is unlikely to quench the focusing magnets directly. At high momenta, when the temperature margin in the focus magnets is small, a quench of the first match coil may cause a quench in the focusing magnet system.

\section{Concluding Comments}

This report shows that the MICE magnets can be quenched safely. The MICE channel coils are short and relatively thin. Thus a whole focus coil or coupling coil will turn completely normal relatively quickly once the coil starts to quench. A relatively low resistance in the magnet circuit is needed to cause either the focusing magnet or the coupling magnet to turn normal through quench back from the magnet mandrel. Reducing the magnet mandrel resistivity reduces the magnet quench back time. Unfortunately, one cannot reduce the quench back time by reducing the mandrel resistivity. High electrical resistivity is inherent to 6061-T6 aluminum. Aluminum with a lower electrical resistivity will not be strong enough to carry the magnetic forces.

No active external quench protection system is needed for any of the MICE magnets. The three focusing magnets can be quenched passively while hooked together in either the flip mode or non-flip mode. The coupling magnets can also be connected in series, but the hot spot temperature in the quenched coil will go up. It is recommended that the coupling coils be powered separately, in order to reduce the charge time so that the coupling magnets can be charged in the same time as the other magnets.

The focusing magnets will have warm diodes and resistors across their coils. The diodes and resistors will reduce the voltage buildup in the magnet circuit as the magnet string is quenching. The coupling magnet will be sub-divided into magnet sub-circuits. Each sub-circuit will have a cold diode and resistor across the sub-circuit to limit the voltage build up during the quench process. The resistor across the inner sub-circuit of the coupling magnet can be used to speed up the magnet quench back process for the whole magnet. This will further reduce voltage built up and the hot spot temperature in the magnet that first quenches.

The MICE cooling channel magnets and the detector magnets form several inductively coupled circuits. Charging or discharging one magnet circuit will induce a voltage in the other magnet circuits. The power supplies must be capable of regulating the current in all of the MICE magnet circuits while all magnets are being charged.

Six $300 \mathrm{~A}, 10 \mathrm{~V}$ power supplies are required for MICE. Six $50 \mathrm{~A}, 10 \mathrm{~V}$ power supplies are required for correction of the two spectrometer end coils and for correction of the current in the two end focus coils at the ends of the cooling channel. It is recommended that a six-phase power supply (after half wave rectification) be used in order to reduce the voltage ripple, but a two-phase power supply (after half wave rectification) may provide a low enough voltage ripple to ensure that the current ripple will be less than 0.03 percent. The power supply current regulation should also be good to 0.03 percent. 
Detailed simulations of coupling from the magnet coils to the mandrel show that the parts of the mandrel that are closest to the magnet coils are better coupled than the parts of the mandrel furthest from the coil current center. When the magnet is charged or discharged at a uniform rate, the current flowing in the mandrel is proportional to di/dt and inversely proportional to the mandrel material resistivity. The energy put into the mandrel inductively is inversely proportional to the charge or discharge time. It is clear, from the simulation, that quenching the magnet heats the mandrel.

It is also clear that quenching a magnet heats the mandrels of other magnets that are coupled to the magnet quenching. The quenching of the focusing magnet is unlikely to quench any other magnet in MICE when the machine operates in the flip mode. In the non-flip mode, a quench of the focusing magnets can cause quenching of other magnets when these magnets are operating at a temperature that is close to the critical temperature of the superconductor at the high field point. Quenching the coupling coil will quench the focusing magnets when the temperature margin is less than about $1.5 \mathrm{~K}$ in the flip mode. Quenching the coupling magnets can also cause quenching of the focusing magnets in the non-flip mode for the very low muon beam beta in the AFC module cases. A quench of the detector solenoid may cause the focusing coils to quench when the focusing magnet temperature margin is low. Quenching the focusing or the coupling magnets is unlikely to quench any of the detector magnets.

\section{Acknowledgements}

This work was supported by the Oxford University Physics Department and the Particle Physics and Astronomy Research Council of the United Kingdom. This work was also supported by the Lawrence Berkeley Laboratory and the Office of Science, United States Department of Energy, under the DOE contract DE-AC03-76SF00098.

\section{References}

[1] "A Proposal to the Rutherford Appleton Laboratory, an International Muon Ionization Cooling Experiment (MICE)," proposed by the MICE Collaboration, 15 December 2002

[2] G. Gregoire, G. Ryckewaert, L. Chevalier, et al, "MICE and International Muon Ionization Cooling Experiment Technical Reference Document,"(October 2004)

[3] W. H. Cherry and J. I Gittlemen, "Thermal and Electrodynamic Aspects of the Superconductive Transition Process," Solid State Electronics 1, p 287 (1960)

[4] A. V. Tollestrup Fermi National Laboratory, private communication about 1975

[5] P. H. Eberhard, M. Alston-Gernjost, M. A. Green, et al, "Quenches in Large Superconducting Magnets," Proceedings of MT-6, Bratislava, Czechoslovakia, p 654, (1977) also LBL-6718 (August 1977)

[6] Z. J. J. Stekly, "Theoretical and Experimental Study of an Unprotected Superconducting Coil Going Normal," Advances in Cryogenic Engineering 8, p. 585, Plenum Press, New York, (1962)

[7] M. Scherer and P. Turowski, "Investigation of the Propagation Velocity of a Normal Conducting Zone in Technical Superconductors," Cryogenics 18 p. 515 (September 1978) 
[8] P. H. Eberhard et al., "The Measurement and Theoretical Calculation of Quench Velocities in Large Fully Epoxy Impregnated Superconducting Coils," IEEE Transactions on Magnetics, MAG-17, No. 5, pp. 1803, (1981)

[9] M. A. Green, "The Role of Quench Back in Quench Protection of a Superconducting Solenoid", Cryogenics 24, p 659, (December 1984).

[10] J. D. Taylor, et al, "Quench Protection for a 2 MJ Magnet", IEEE Transactions on Magnetics MAG-15, No. 1, p. 855, (1979)

[11] M. A. Green, "Design Conditions for Fail-Safe Quenching of a High-Current Density Superconducting Solenoid Magnet with a Shorted Secondary Circuit", LBL-14859, September 1982.

[12] M. A. Green, "Quench Back in Thin Superconducting Solenoid Magnets", Cryogenics 24, p 3, (1984)

[13] Jon Zbasnik of the Lawrence Berkeley Laboratory, private communication concerning the failure of one of the ALS Superbend RDK-415D coolers.

[14] M. A. Green and S. Q. Yang, "Heat Transfer into and within the 4.4 K Region and the $40 \mathrm{~K}$ Shields of the MICE Focusing and Coupling Magnets," Oxford University Physics Department Report for the MICE project, 28 April 2004

[15] Handbook of Materials for Superconducting Machinery, Metal and Ceramics Information Center, MIC-MB-04, National Bureau of Standards, Jan. 1977

[16] W. R. Smythe, Static and Dynamic Electricity, McGraw Hill Book Co., New York, (1950)

[17] L. Li, "High Performance Pulsed Magnets: Theory, Design and Construction. PhD Thesis, Katholieke Universiteit Leuven, Belgium, 1998.

[18] A. Führer, K. Heidemann and W. Nerreter, Grundgebiete der Elektrotechnik, Band 2: Zeitabhängige Vorgänge, Carl Hanser Verlag, München, 1994.

[19] G. K. White and P. J. Meeson. Experimental Techniques in Low-Temperature Physics. Oxford University Press, Oxford, 2002.

[20] Femlab 3 Electromagnetic Module User's Guide. COMSOL, 2004.

[21] Femlab 3 Modelling Guide. COMSOL, 2004.

[22] J. D. Jackson. Classical Electrodynamics. ${ }^{\text {rd }}$ edition, John Weiley \& Sons, 1998. 